\title{
Canalization and developmental stability of the yellow-necked mouse (Apodemus flavicollis) mandible and cranium related to age and nematode parasitism
}

Vida Jojić (* $^{*}$, Borislav Čabrilo², Olivera Bjelić-Čabrilo², Vladimir M. Jovanović1,3,4, Ivana Budinski', Mladen Vujošević ${ }^{\text {and Jelena Blagojević }}$

\begin{abstract}
Background: Mammalian mandible and cranium are well-established model systems for studying canalization and developmental stability (DS) as two elements of developmental homeostasis. Nematode infections are usually acquired in early life and increase in intensity with age, while canalization and DS of rodent skulls could vary through late postnatal ontogeny. We aimed to estimate magnitudes and describe patterns of mandibular and cranial canalization and DS related to age and parasite intensity (diversity) in adult yellow-necked mice (Apodemus flavicollis).

Results: We found the absence of age-related changes in the levels of canalization for mandibular and cranial size and DS for mandibular size. However, individual measures of mandibular and cranial shape variance increased, while individual measures of mandibular shape fluctuating asymmetry (FA) decreased with age. We detected mandibular and cranial shape changes during postnatal ontogeny, but revealed no age-related dynamics of their covariance structure among and within individuals. Categories regarding parasitism differed in the level of canalization for cranial size and the level of DS for cranial shape. We observed differences in age-related dynamics of the level of canalization between non-parasitized and parasitized animals, as well as between yellow-necked mice parasitized by different number of nematode species. Likewise, individual measures of mandibular and cranial shape FA decreased with age for the mandible in the less parasitized category and increased for the cranium in the most parasitized category.

Conclusions: Our age-related results partly agree with previous findings. However, no rodent study so far has explored age-related changes in the magnitude of FA for mandibular size or mandibular and cranial FA covariance structure. This is the first study dealing with the nematode parasitism-related canalization and DS in rodents. We showed that nematode parasitism does not affect mandibular and cranial shape variation and covariance structure among and within individuals. However, parasite intensity (diversity) is related to ontogenetic dynamics of the levels of canalization and DS. Overall, additional studies on animals from natural populations are required before drawing some general conclusions.
\end{abstract}

\footnotetext{
${ }^{*}$ Correspondence: vjojic@ibiss.bg.ac.rs

${ }^{1}$ Department of Genetic Research, Institute for Biological Research "Siniša

Stanković" - National Institute of Republic of Serbia, University of Belgrade, Belgrade, Serbia

Full list of author information is available at the end of the article
}

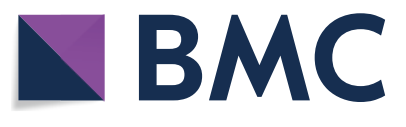

(c) The Author(s) 2021. Open Access This article is licensed under a Creative Commons Attribution 4.0 International License, which permits use, sharing, adaptation, distribution and reproduction in any medium or format, as long as you give appropriate credit to the original author(s) and the source, provide a link to the Creative Commons licence, and indicate if changes were made. The images or other third party material in this article are included in the article's Creative Commons licence, unless indicated otherwise in a credit line to the material. If material is not included in the article's Creative Commons licence and your intended use is not permitted by statutory regulation or exceeds the permitted use, you will need to obtain permission directly from the copyright holder. To view a copy of this licence, visit http://creativecommons.org/licenses/by/4.0/. The Creative Commons Public Domain Dedication waiver (http://creativeco mmons.org/publicdomain/zero/1.0/) applies to the data made available in this article, unless otherwise stated in a credit line to the data. 
Keywords: Covariation, Developmental homeostasis, Developmental instability, Fluctuating asymmetry, 2D Geometric morphometrics, Intestinal helminths, Mammals, Skull, Postnatal ontogeny, Rodents

\section{Background}

Developmentally and functionally complex morphological structures, such as mammalian mandible and cranium, are well-established model systems for studying canalization, developmental stability (DS), and morphological integration, recognized by Hallgrímsson et al. [1] as three main components of phenotypic variability. Canalization and DS also represent two elements of developmental homeostasis or homeorhesis, the mechanism responsible for ensuring phenotypic constancy in organisms despite the great variability of genetic and environmental features [2-4]. According to early explanations of canalization and DS, the former is considered as the buffering of developmental processes against environmental and mutational perturbations, and the latter as the ability of developmental processes to buffer random developmental noise that arises within the developmental processes themselves $[5,6]$. Similarity between canalization and DS lies in the fact that both limit phenotypic variation. The key distinction between them is in the origin of potential factors contributing to phenotypic variation in such a way that environmental perturbations arise outside of an individual, while developmental noise, as stochastic fluctuations in developmental processes, arises within an individual [1,7-9]. Although developmental noise is not caused by environmental or genetic variation, environmental and genetic factors can affect developmental processes that mediate its expression and thus influence DS $[9,10]$.

Symmetric traits in different individuals develop under different genetic and environmental conditions, whereas in the same individuals they share the same genome and experience the same environmental conditions $[8$, 9]. Therefore, the deviations from perfect symmetry are caused by developmental disruptions arising within an individual. Consequently, the differences in the amount of among-individual variation (Ind) indicate differences in ability to canalize development against genetic and environmental stresses, while the differences in the amount of within-individual variation or fluctuating asymmetry (FA), i.e. random differences between the two sides in bilaterally symmetric traits [11, 12], indicate differences in ability to buffer development against random developmental noise. Thus, the amount of Ind is used to measure canalization and the amount of FA serves as the measure of DS. Lower level of Ind and FA signify a higher level of canalization and DS, respectively. Because ancestral states of canalization and DS for a structure are unknown, they can only be estimated by comparison with some reference state $[8,13]$.

The factors that may disturb developmental homeostasis can be of environmental or genetic origin [14]. Traditional and geometric morphometric methods have been used frequently in a wide range of organisms, from plants to humans, for examining whether various environmental and genetic factors disrupt the level of canalization and DS $[1,4,9,12,14-20]$. In the 1990s geometric morphometric methods offered new tools for exploring patterns of morphological variation, i.e. covariance structures, both among and within individuals, in relation to potential environmental and genetic stressful factors, as well as for inspecting relationships between canalization and DS [1, 9, 20-22]. Ontogenetic dynamics of magnitude and pattern of canalization/DS [1,23-26], as well as their associations with fitness $[1,7,9,14,20]$ have also been examined.

Within rodents, canalization and DS of skull traits were explored using laboratory-bred mice (Mus musculus domesticus; Calomys expulsus) and rats (Sigmodon fulviventer; Rattus norvegicus albinus), as well as rodents from wild populations. Laboratory-based studies delivered important knowledge regarding relations between magnitude/pattern of variation among and within individuals and environmental [27-30] or genetic $[18,31-34]$ factors, relationships between patterns of Ind and FA as evidence of whether the same developmental mechanisms generate canalization and DS [21], ontogenetic changes in magnitude of variation and covariance structure among individuals [23-25, 35-37], and genetic architecture of FA [38]. Considering studies that involved specimens from wild rodent populations, the majority of them investigated associations between FA levels of meristic [39, 40] and metric [41-47] mandibular and cranial characteristics with environmental and genetic perturbations, while few of them compared patterns between Ind and FA to infer whether developmental mechanisms behind canalization and DS are closely related $[45,48$, 49]. Moreover, examinations of parasite (viral) infections effects on host (rodents from wild populations) morphology found that viruses can disrupt host development affecting mean cranial shape and canalization $[50,51]$.

Although numerous studies have reported a relationship between DS and parasite infections, reflected in increased levels of FA in host individuals [14, 17, 52], inside vertebrate groups this association was studied mostly in some fish and avian species, whereas within 
mammals it has so far been examined only in humans and reindeer (Rangifer tarandus) [17, 52]. According to Møller [52], there are at least three reasons responsible for this relationship. First, individuals with elevated levels of FA may be more susceptible to parasitism; host FA would reflect an inefficiency of the immune system to resist infection [52-54]. Second, individuals with higher levels of FA may more often be exposed to parasites; if competitive ability depends on body condition, developmentally unstable individuals will more often be restricted to poor environments with elevated risk of encountering parasites [14, 52, 54, 55]. Third, parasites may disrupt host development and be the direct cause of instability [52]; host FA should be directly related to parasite virulence, parasite load, or both [54, 56-58].

The yellow-necked mouse (Apodemus flavicollis Melchior, 1834), common in the Western Palearctic region, is abundantly distributed throughout the territory of Serbia. The nematode fauna of $A$. flavicollis is well documented in several European countries [59-62], as well as in Serbia [63-66]. Additionally, this mouse species is characterized by the presence of the oldest known chromosome polymorphism [67], i.e. supernumerary or B chromosomes (Bs) $[68,69]$. Therefore, wild-caught $A$. flavicollis has been used as a model organism for various surveys of Bs in mammals [70, 71], while its mandible and cranium have been used as model systems not only for examining phenotypic effects of Bs [72-74], including those on canalization, DS and morphological integration $[40,45$, 75], but also for exploring morphological modularity and comparison of traditional and geometric morphometric procedures for analyzing it [76]. Earlier investigations in A. flavicollis found that Bs do not disturb developmental homeostasis in their carriers [40, 45], but they play a significant role in structuring cranial variation [45]. In addition, after analyzing the possible influence of Bs on genes involved in immune response and helminth burden in A. flavicollis, Adnađević et al. [77] concluded that animals with and without Bs have the same endpoint immune response to parasites yet achieved through different pathways.

Our initial aim in the present study was to inspect canalization and DS of the mandible and cranium in relation to intestinal nematode parasitism in adult specimens of A. flavicollis from the territory of Serbia. Moreover, nematode infections are usually acquired in early life and increase in intensity with age [77, 78], while canalization and DS of rodent skulls could vary through late postnatal ontogeny [23-25, 35-37]. Consequently, we aimed to examine canalization and DS of the mandible and cranium in relation to age of $A$. flavicollis adults. Thus, both magnitude (for size and shape) and pattern (for shape) of variation among and within individuals were explored, and compared, separately across age categories and categories regarding parasitism.

With regards to the age-related dynamics of canalization and DS, and in line with previous findings in laboratory-reared rodents, we tested the following hypotheses: (1) Variance among individuals (for mandibular and cranial size and shape) will decrease with age, i.e. the highest levels of canalization for mandibular and cranial size and shape will be in the oldest yellow-necked mice; (2) There will be no change in the magnitude of shape variation within individuals through late ontogeny, i.e. we assume the absence of age-related dynamics of the levels of DS for mandibular and cranial shape; (3) Mandibular and cranial shape will differ across ontogenetic stages, as well as mandibular and cranial covariance structure among individuals. To the best of our knowledge, no rodent study has explored either changes in the magnitude of mandibular size variation within individuals through late ontogeny, or ontogenetic dynamics of mandibular and cranial FA covariance structure, so we could not make any predictions.

Regarding the relationship of nematode parasitism with canalization and DS, with no assumption of any of the three reasons proposed by Møller [52], we tested the following hypotheses: (1) Infections by intestinal nematodes may be associated with the levels of canalization and DS in A. flavicollis. Thus, we expect that parasitized animals possess lower levels of canalization (for mandibular and cranial size and shape) and DS (for mandibular size and mandibular and cranial shape) compared to non-parasitized yellow-necked mice; and (2) Infections by intestinal nematodes may be linked with the shape variation among individuals and the patterns of variation among and within individuals of $A$. flavicollis. Accordingly, we expect differences in the mandibular and cranial shape variation among individuals, as well as differences in mandibular and cranial patterns of canalization and DS, between different categories of parasitized animals.

\section{Methods \\ Data collection and sample composition}

Yellow-necked mice (Apodemus flavicollis) were collected between 2011 and 2015 from 21 localities in Serbia (Fig. 1). Mice were trapped using Longworth traps baited with sardines and wheat. During dissection, each animal was sexed by gonad inspection. ISSR-PCR method was used to distinguish A. flavicollis from A. sylvaticus [79]. Chromosomes were prepared directly from bone marrow according to the standard procedure [80]. The presence of $\mathrm{B}$ chromosomes (Bs) was determined by analyzing 30 metaphase figures per specimen using counting tool in software Analyst [81]. All animals characterized by more than 48 chromosomes (standard chromosome set) 


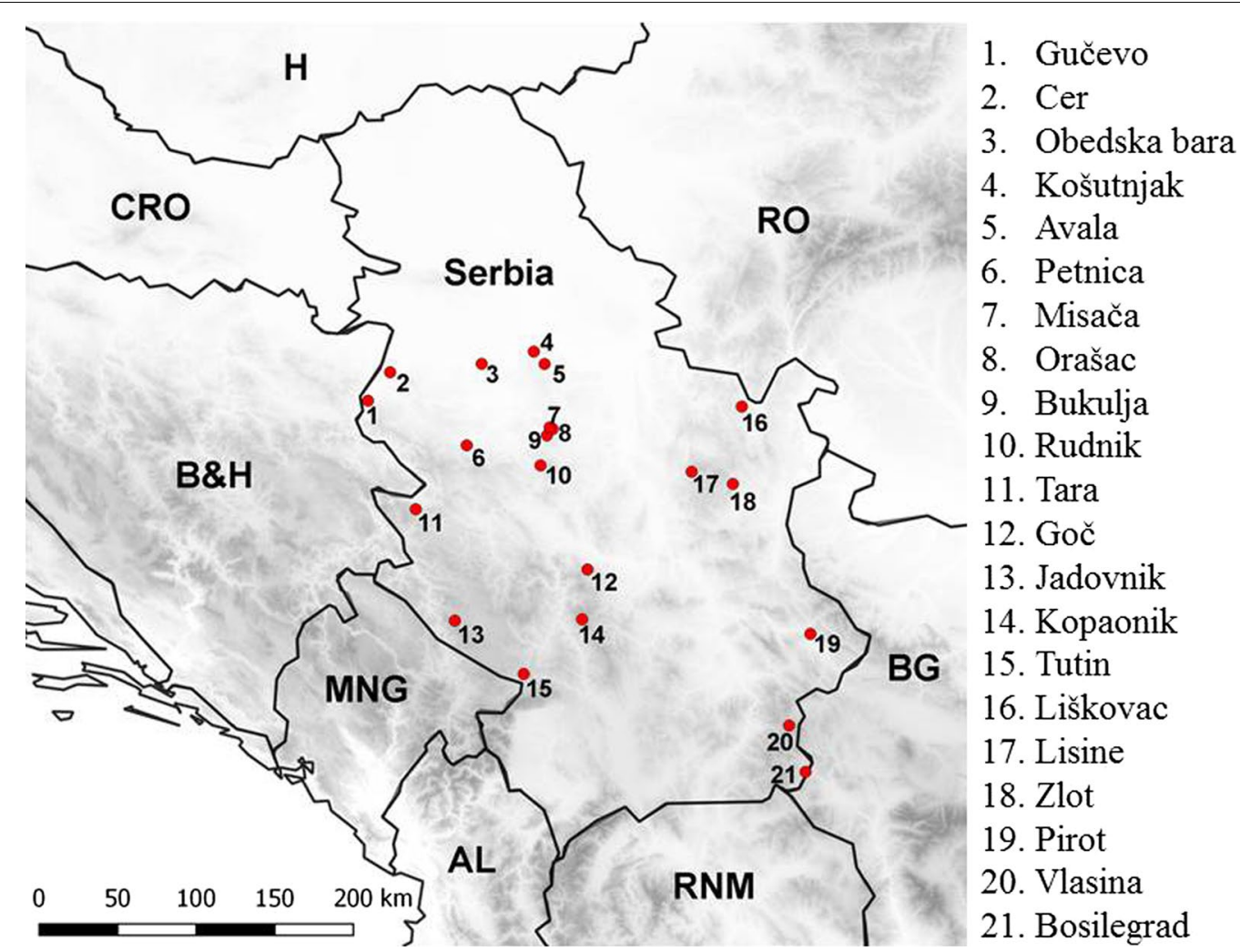

Fig. 1 Geographic distribution of the yellow-necked field mouse (Apodemus flavicollis) localities from Serbia

were considered to have Bs. The age of each individual was estimated based on the weight of dry eye lens [82]. The intestinal tract was dissected from each animal and nematode parasites (Aonchotheca annulosa, Aspiculuris tetraptera, Eucoleus sp., Heligmosomoides polygyrus, Mastophorus muris, Rictularia proni, Syphacia frederici, S. stroma, and Trichuris muris) were identified using keys by Ryzhikov et al. [83] and Genov [60]. The yellow-necked mouse sample consisted of uninfected and infected individuals, with the latter hosting one to five different species of intestinal nematodes [64]. Mandibles and crania were cleaned by exposure to dermestid beetles.

We studied a total of 275 mandibles and 320 crania of adult animals. Images $(2272 \times 1520$ pixels resolution) of left and right mandibles in the labial view and images $(2272 \times 1520$ pixels resolution) of crania in the ventral view, supported by modeling clay with the palate positioned parallel to the photographic plane, were taken with a NIKON Coolpix 4500 digital camera by the same person (VJ). Mandibles are more fragile than crania and during cleaning and imaging some of them were damaged, particularly in the region of the coronoid process. As studies of mandibular fluctuating asymmetry (FA) require both intact mandibles (left and right), their sample size was smaller than sample size of crania.
Using TpsDig software [84, 85], the same observer (VJ) recorded 14 and 33 (14 paired and five median) twodimensional landmarks on the mandible and cranium, respectively (Fig. 2). Anatomical definitions of landmarks are given in Additional file 1: Table S1.

Prior to digitizing 2D landmarks on mandibles, all images of left mandibles were reflected to right side to avoid a bias when locating landmarks on images of the left and right sides of biological structures [20]. To assess measurement error due to positioning and imaging of 3D biological structures such as the cranium, we conducted Procrustes analysis of variance (ANOVA) [86, 87] for a set of 96 yellow-necked mice (29.7\% of the total). Two images of each cranium were taken, and each image was digitized twice. The mean square for FA and individual variation exceeded the error component (effect of imaging) by fivefold and 64-fold, respectively. Therefore, all the subsequent analyses were based on a single image per cranium. However, as replicates are necessary for studies of FA, each image of the right and the mirror-reflected left mandible, as well as each image of the cranium, was digitized twice in two separate sessions.

In an earlier study concerning sex ratio variation of intestinal nematode infrapopulations in A. flavicollis, Jovanović et al. [66] distinguished three age categories 


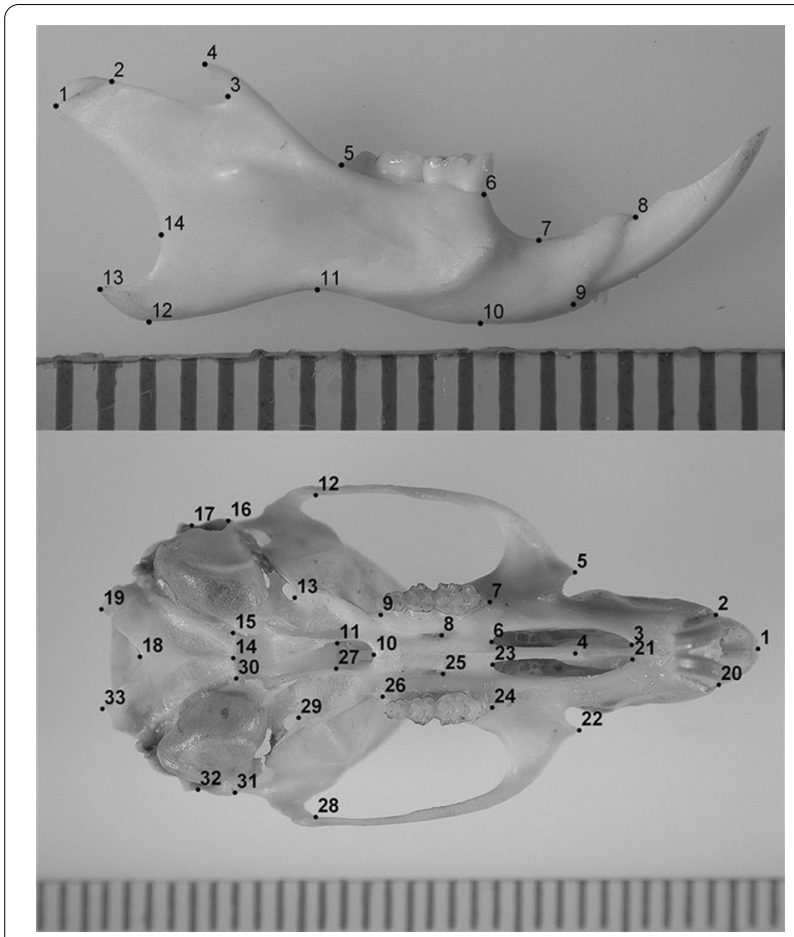

Fig. 2 Landmarks recorded on the labial view of the mandible and the ventral surface of the cranium of the yellow-necked field mouse (Apodemus flavicollis). See Additional file 1: Table S1, for landmark definitions

Table 1 Sample composition

\begin{tabular}{lllll}
\hline & & $(\mathbf{P 0}, \mathbf{P 1}, \mathbf{P 2}, \mathbf{P 3})$ & $\mathbf{( m , \mathbf { f } )}$ & $\mathbf{( B 0 , B + )}$ \\
\hline Mandible & A1 & $(29,29,16,3)$ & $(37,40)$ & $(57,20)$ \\
& A2 & $(15,41,36,18)$ & $(63,47)$ & $(72,38)$ \\
& A3 & $(2,26,34,26)$ & $(39,49)$ & $(56,32)$ \\
Cranium & A1 & $(41,36,27,3)$ & $(52,55)$ & $(77,30)$ \\
& A2 & $(13,42,45,19)$ & $(71,48)$ & $(79,40)$ \\
& A3 & $(2,28,36,28)$ & $(44,50)$ & $(61,33)$ \\
\hline
\end{tabular}

A1-first age category (animals with dry eye lens mass $\leq 15 \mathrm{mg}$ ), A2-second age category (animals with $15-25 \mathrm{mg}$ of dry eye lens mass), A3-third age category (animals with dry eye lens mass $>25 \mathrm{mg}$ ) according to Jovanović et al. yyyy[66]; P0 —non-parasitized animals, $\mathrm{P} 1$ —animals parasitized by one nematode species, $\mathrm{P} 2$-animals parasitized by two nematode species, $\mathrm{P} 3-$ animals parasitized by three to five nematode species. $\mathrm{m}$-males, $\mathrm{f}-$ females; B0-animals with standard karyotype (without B chromosomes, Bs), B +animals with Bs

of host mice, estimated from dry eye lens weight. Based on the same criterion, we also recognized the same three age categories of adult $A$. flavicollis, i.e. animals whose dry eye lens mass in $\mathrm{mg}$ was: $\leq 15 \mathrm{mg}$ (A1 category), 15-25 mg (A2 category), and $>25 \mathrm{mg}$ (A3 category) (Table 1). According to the presence and number of nematode species detected within a single individual (parasite diversity), we recognized four categories regarding parasitism: non-parasitized animals (P0 category), animals parasitized by one (P1 category), two (P2 category), and three to five (P3 category) nematode species (Table 1). Dealing with limited sample sizes of adult wildcaught specimens of $A$. flavicollis belonging to particular categories regarding parasitism and age (overall 12 categories whose sample sizes are too small for statistical tests), we were in a rather difficult situation to separate effects of parasitism from the effects of aging on canalization and DS. Consequently, all the following analyses were performed separately for age categories and categories regarding parasitism.

\section{Preliminary analyses}

Spearman's rank correlation coefficient revealed statistically significant relationship between categories regarding parasitism and age categories in both mandible $\left(\mathrm{r}_{\mathrm{s}}=0.413 ; \mathrm{P}<0.05\right)$ and cranium $\left(\mathrm{r}_{\mathrm{s}}=0.423 ; \mathrm{P}<0.05\right)$ samples, indicating that parasite infection (parasite diversity) is higher in older animals. Additionally, we calculated body condition indices (BCI) as the residuals of linear regression of total body mass on standard length [88]. One-way analysis of variance (ANOVA) showed no difference in $\mathrm{BCI}$ among categories regarding parasitism $\left(\mathrm{F}_{3,316}=1.70, \mathrm{P}=0.1672\right)$, indicating that parasite diversity does not affect the body condition of animals.

\section{Size analyses}

Within each category, the landmark coordinates of original and mirrored configurations of both replicates were aligned simultaneously using a generalized Procrustes analysis (GPA) [89-91] to extract centroid size (CS) and superimposed Procrustes coordinates. Procrustes ANOVA $[86,87]$ was performed to partition overall size variation into individual variation (effect of Individuals, Ind), directional asymmetry (effect of Side, DA), fluctuating asymmetry (effect of Individual-by-Side interaction, FA), measurement error component (effect of digitizing), and variation caused by additional main effects of sex and presence of B chromosomes (Bs). Parametric F-tests in ANOVA of CS were used to determine whether size variation among individuals, DA, FA, and additional effects of sex and presence of Bs were significant within each category. For datasets with object symmetry, i.e. cranial datasets, there are no effects of Side or Individual-by-Side interaction, nor is there asymmetric CS (size differences between sides) due to the fact that CS is computed for the entire configuration (including both sides) [87]. To check for potential mandibular size antisymmetry, asymmetric CS (size differences between left and right mandibles) was inspected for signs of bimodality using the Kolmogorov-Smirnov test of normality [12, 92]. 
For mandibular and cranial size, the level of canalization was assessed by among-individual size variance [18, 23, 25]. Mandibular among-individual size variance was calculated as the variance of symmetric CS ( $\left.\operatorname{Var}_{\text {SymmCS }}\right)$, while cranial among-individual size variance was calculated as the variance of $C S\left(\operatorname{Var}_{C S}\right)$. To estimate the significance of differences in size variance among categories, Levene's test was performed on absolute size differences $\left(\right.$ SymmCS $-S_{j}$ SymmCS ${ }_{\text {mean }}$ for the mandible; $\mathrm{CS}_{\mathrm{j}}-\mathrm{CS}_{\text {mean }}$ for the cranium).

For mandibular size, the level of developmental stability (DS) was estimated by the level of size FA using FA10a index $[12,30]$. To estimate the significance of differences in mandibular size FA among categories, Levene's test was performed on asymmetric CS.

In addition, to determine the association of individual measures of mandibular and cranial size variance and mandibular size FA with age, absolute size differences and asymmetric CS were regressed on dry eye lens mass (age) within the whole sample for age categories, as well as within each category regarding parasitism.

\section{Shape analyses}

Within each category, to eliminate the influence of allometry, all individuals were standardized to the mean CS for corresponding category using the Standard6b program [93]. Subsequently, Procrustes ANOVA [86, 87] was performed to partition overall shape variation into individual variation, directional asymmetry, fluctuating asymmetry, measurement error component, and variation caused by additional main effects of sex and presence of B chromosomes (Bs). Parametric F-tests in Procrustes ANOVA were used to determine whether shape variation among individuals, DA, FA, and additional effects of sex and presence of Bs were significant. To check for potential shape antisymmetry, we visually examined the plots of scores for the first five PCs of the vectors of individual signed asymmetries, which explained more than $50 \%$ of the asymmetric component of shape variation. If there is bimodality in the data, there should be a clustering of the data points. Additionally, each of the five PCs scores was inspected for signs of bimodality using the KolmogorovSmirnov test.

For mandibular and cranial shape, the level of canalization was estimated by among-individual shape variance $[18,23,25]$. Variance in shape $\left(\operatorname{Var}_{\text {shape }}\right)$ was calculated for Procrustes distances (Pds), computed from the symmetric component of shape variation, based on the standard metric for variance. To assess the significance of the differences in shape variance among categories, Levene's test was performed on these Pds.

For mandibular and cranial shape, the level of DS was estimated by the level of shape FA using FA10a index of Palmer \& Strobeck [12]. To assess the significance of differences in shape FA among categories, Levene's test was performed on shape FA scores (in units of Pd) calculated from the asymmetric component of shape variation $[18,23,25,30]$.

In addition, to determine the association of individual measures of mandibular and cranial shape variance and FA with age, Pds and shape FA scores were regressed on dry eye lens mass (age) within the whole sample for age categories, as well as within each category regarding parasitism.

Previously size-standardized datasets were combined in a single dataset and averaged by individual. To quantify the mean shape differences between categories in the symmetric component of shape variation (individual variation, Ind), Pds were computed. To assess their statistical significance we used a permutation test (with 10000 permutation runs) under the null hypothesis of equal category means, followed by Bonferroni adjustment. Afterward, principal component analysis (PCA) was performed on the covariance matrix of symmetric component of shape variation and displayed as a scatterplot of the first two principal components ( $\mathrm{PC} 1$ and PC2) [25]. TPS deformation grids [94] were used to visually detect the magnitude and direction of Ind shape changes among categories separated along PC1 axis. As presented in Table 1, within P1 and P2 categories the number of specimens of A1, A2, and A3 categories is more or less balanced, whereas P0 category mostly comprises the youngest (A1) and P3 category almost completely consists of older (A2 and A3) individuals. To decipher parasitism- and age-related changes in the symmetric component of shape variation we conducted discriminant function analysis (DFA) between P0 and P3 categories and multivariate regression of their shape variables onto dry eye lens mass.

To test whether categories differ in the pattern of symmetric (Ind) and asymmetric (FA) shape variation, we compared the respective covariance matrices by matrix correlation. The significance of matrix correlation was obtained using the matrix permutation test with 10000 iterations against the null hypothesis of complete dissimilarity between the respective covariance matrices [95], by permuting landmarks and including the diagonal entries of the matrices.

Spearman's rank correlation, Kolmogorov-Smirnov and Levene's tests, as well as ANOVA and regressions, were performed using Statistica v. 5.1 [96]. All other analyses were done in MorphoJ [97]. 


\section{Results}

\section{Age categories-Size}

Parametric F-tests in ANOVAs of centroid size (CS) reveal that mandibular and cranial size variation among individuals, as well as directional asymmetry (DA) and fluctuating asymmetry (FA) for the mandible, are all highly significant in all age categories (Additional file 2: Table S2). Additional effect of sex is significant in A2 and A3 categories, whereas effect of presence of B chromosomes (Bs) is insignificant within each age category. Although significant, DA accounts for a fairly small percentage of the total mandibular size variation $(0.40 \%, 0.26 \%$, and $0.49 \%$ in A1, A2, and A3 category, respectively). Kolmogorov-Smirnov tests disclose that CS asymmetry is normally distributed, indicating the absence of antisymmetry in mandibular size within each age category.

Both variance of symmetric CS ( $\operatorname{Var}_{\text {SymmCS }}$ ) for mandibular size and variance of CS $\left(\operatorname{Var}_{C S}\right)$ for cranial size are the highest in A2 category, followed by A3 and A1 for the mandible and A1 and A3 for the cranium (Table 2). Levene's tests performed on absolute size differences $\left(\right.$ SymmCS$_{\mathrm{j}}-$ SymmCS$_{\text {mean }}$ for the mandible and $\mathrm{CS}_{\mathrm{j}}-$ $\mathrm{CS}_{\text {mean }}$ for the cranium) reveal no significant differences in size variance among age categories (mandible: $F_{2}$, ${ }_{272}=0.98, \mathrm{P}=0.3753$; cranium: $\mathrm{F}_{2,317}=2.44, P=0.0885$ ). Besides, regressions of absolute size differences on dry eye lens mass show no age-related changes in mandibular and cranial size variance (mandible: $r=0.0366$, $P=0.5455$; cranium: $\mathrm{r}=0.0099, P=0.8600)$.

For mandibular size the level of FA (SizeFA10a index) is the highest in A3 and the lowest in A2 category (Table 2). Levene's test performed on asymmetric CS discloses no statistically significant differences in the

Table 2 Levels of canalization and developmental stability (DS) for the mandible and cranium

\begin{tabular}{|c|c|c|c|c|c|}
\hline & $\operatorname{Var}_{\text {SymmCS }}$ & $\operatorname{Var}_{C S}$ & Var $_{\text {shape }}$ & SizeFA10a & ShapeFA10a \\
\hline \multicolumn{6}{|c|}{ Mandible } \\
\hline A1 & 2589.74 & - & 0.00102 & 6.04 & 0.00414 \\
\hline A2 & 3349.65 & - & 0.00109 & 5.89 & 0.00357 \\
\hline A3 & 2866.80 & - & 0.00116 & 8.46 & 0.00345 \\
\hline \multicolumn{6}{|c|}{ Cranium } \\
\hline A1 & - & 7641.06 & 0.00037 & - & 0.00134 \\
\hline A2 & - & 9658.27 & 0.00038 & - & 0.00129 \\
\hline $\mathrm{A} 3$ & - & 7434.28 & 0.00043 & - & 0.00140 \\
\hline
\end{tabular}

Age categories: A1 - first age category, A2 — second age category, A3 - third age category. $\operatorname{Var}_{\text {SymmCS }}$ - mandibular among-individual size variance; $\operatorname{Var}_{C S}$ cranial among-individual size variance; $\mathrm{Var}_{\text {shape }}$ - variance in mandibular/cranial shape; SizeFA10a-level of fluctuating asymmetry (FA) for mandibular size; ShapeFA10a-level of fluctuating asymmetry (FA) for mandibular/cranial shape. $\mathrm{FA} 10 \mathrm{a}=0.798 \sqrt{ } \mathrm{MS}_{\mathrm{sj}}-\mathrm{MS}_{\mathrm{m}}$ calculated from the values given in Additional files 2 and 3: Tables S2 and S3 level of mandibular size FA among age categories $\left(\mathrm{F}_{2}\right.$, $\left.{ }_{272}=0.91, P=0.5838\right)$. Moreover, regression of asymmetric CS versus dry eye lens mass indicates the absence of the association of individual measures of size FA with age $(\mathrm{r}=-0.0332, P=0.5838)$.

\section{Age categories-shape}

As shown by parametric F-tests in Procrustes ANOVAs of shape (Additional file 3: Table S3), mandibular and cranial shape variation among individuals, as well as directional asymmetry (DA) and fluctuating asymmetry (FA), are all highly significant in all age categories. Although additional effect of sex is significant only for the mandible in A1 and A3 categories, it accounts for a smaller percentage of the total shape variation than individual variation and FA (A1 category: Sex $=2.10 \%$; Individual $=76.31 \%$; Ind $\times$ Side $=14.71 \%$; A3 category: Sex $=1.76 \%$; Individual $=82.77 \%$; Ind $\times$ Side $=9.88 \%$ ). Additional effect of presence of B chromosomes (Bs) is significant only for the mandible in A1 category where it accounts for smaller percentage of the total shape variation than individual variation and $\mathrm{FA}(\mathrm{Bs}=1.64 \%$; Individual $=76.31 \%$; Ind $\times$ Side $=14.71 \%$ ). Although significant, DA accounts for a fairly small percentage of the total mandibular and cranial shape variation (mandible: $1.06 \%, 1.41 \%$, and $1.47 \%$ in $\mathrm{A} 1, \mathrm{~A} 2$, and $\mathrm{A} 3$ category, respectively; cranium: $1.90 \%, 1.62 \%$, and $1.83 \%$ in $\mathrm{A} 1$, A2, and A3 category, respectively). In all age categories the visual examinations of the scatter plots for the first five PCs of the vectors of individual signed asymmetries reveal no evidence for clustering of the data points. Additionally, Kolmogorov-Smirnov tests indicate that distributions of each of the five PCs scores don't show a significant departure from normality. Thus, these asymmetries can be assigned to FAs.

For both mandible and cranium, among-individual shape variance ( $\operatorname{Var}_{\text {shape }}$ ) is the lowest in A1 and the highest in A3 category (Table 2). Levene's tests performed on Procrustes distances (Pds) reveal no significant differences in shape variance among age categories (mandible: $F_{2,272}=0.39, P=0.6769$; cranium: $F_{2,317}=1.81$, $P=0.1654$ ). However, regressions of Pds on dry eye lens mass are statistically significant (mandible: $r=0.1241$, $P=0.0397$; cranium: $\mathrm{r}=0.1504, P=0.0070)$ indicating their increase with age.

For mandibular shape the level of FA (ShapeFA10a index) is the highest in A1 and the lowest in A3 category, whereas for cranial shape the level of FA (ShapeFA10a index) is the highest in A3 and the lowest in A2 category (Table 2). Levene's tests performed on shape FA scores unveil no significant differences in the level of mandibular and cranial shape FA among age categories (mandible: $F_{2,272}=2.13, P=0.1211$; cranium: $F_{2}$, 
$\left.{ }_{317}=0.66, P=0.5162\right)$. However, regression of mandibular Procrustes FA scores versus age is statistically significant $(r=-0.1667, P=0.0056)$ indicating their decline with age, while regression of cranial Procrustes FA scores versus age is not statistically significant $(r=0.0836$, $P=0.1359$ ).

All pairwise comparisons of the analyzed age categories reveal statistically significant mean shape differences in symmetric component of shape variation (mandible: Pd $(\mathrm{A} 1$ vs. $\mathrm{A} 2)=0.0280, P<0.0001$; $\mathrm{Pd}(\mathrm{A} 1$ vs. $\mathrm{A} 3)=0.0362$, $P<0.0001$; Pd (A2 vs. A3) $=0.0109, P<0.0001$; cranium: $\mathrm{Pd}(\mathrm{A} 1$ vs. $\mathrm{A} 2)=0.0206, P<0.0001$; $\mathrm{Pd}(\mathrm{A} 1 \mathrm{vs}$. $\mathrm{A} 3)=0.0309, \quad P<0.0001 ; \quad \mathrm{Pd} \quad(\mathrm{A} 2 \quad$ vs. $\quad \mathrm{A} 3)=0.0109$, $P<0.0001)$. As illustrated by scatterplots of the first two principal components ( $\mathrm{PC} 1$ and $\mathrm{PC} 2$ ) for symmetric shape variation, age categories separate from each other along $\mathrm{PC} 1$ axis, although there is a larger overlap between A2 and A3 categories for the mandible than for the cranium (Fig. 3). Mandibular shape changes between the youngest (A1 category) and two older (A2 and A3 categories) groups are visible almost throughout the whole structure, except the region of condylar process. Additionally, in the youngest yellow-necked mice the posterior part of the mandible (in the regions of angular and coronoid processes) is narrower and the anterior part (alveolar region, i.e. molar and incisor zones) is longer, whereas in older specimens the posterior mandibular part is wider and the alveolar region is shorter (Fig. 3a). Considering cranial shape modifications between the youngest and the oldest (A3 category) individuals, the youngest yellow-necked mice have crania with broader basicranial region, enlarged regions of the palate and foramen magnum, wider and shorter facial region and more laterally expanded zygomatic arches (Fig. 3b).

For both mandible and cranium the patterns of symmetric (Ind) and asymmetric (FA) shape variation is similar between all age categories (Table 3).

\section{Categories regarding parasitism-size}

According to parametric F-tests in ANOVAs of centroid size (CS) (Additional file 4: Table S4), mandibular and cranial size variation among individuals is highly significant in all categories regarding parasitism. Directional asymmetry (DA) and fluctuating asymmetry (FA) for the mandible are also highly significant in all categories, except for DA in P3 category which is significant at $P=0.0310$. Additional effect of sex is significant in P3 category for the mandible and in P1 and P3 categories for the cranium. Effect of presence of B chromosomes (Bs) is significant only for the mandible within P1 category at $P=0.0353$. Although significant, DA accounts for a fairly small percentage of the total mandibular size variation $(0.22 \%, 0.14 \%, 0.13 \%$, and $0.25 \%$ in P0, P1, P2, and P3 category, respectively). Kolmogorov-Smirnov tests show
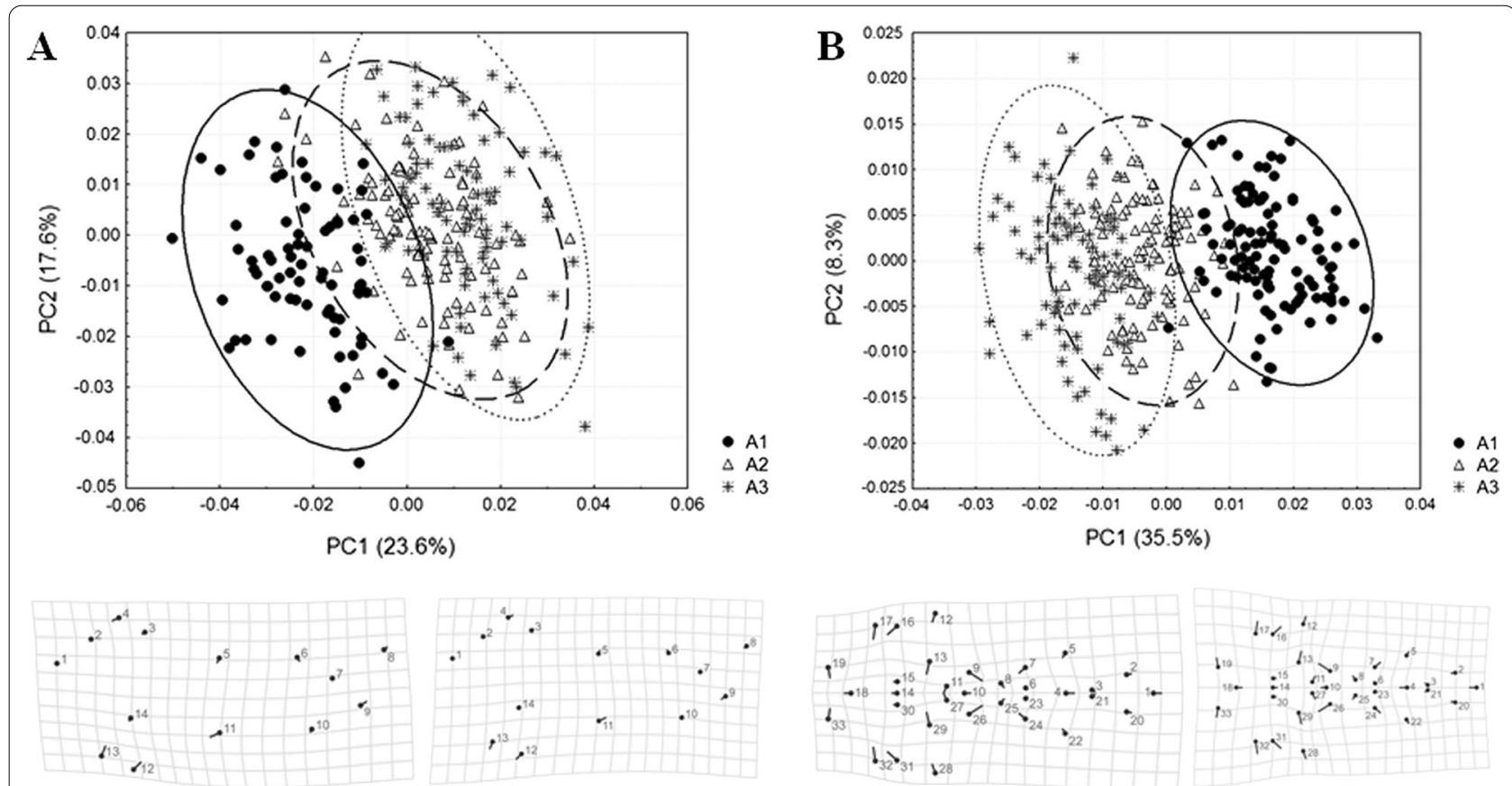

Fig. 3 Scatterplots of the first two principal components (PC1 vs. PC2) from the symmetric component of shape variation (individual variation, Ind) for the mandible (a) and cranium (b). Age categories: A1 — first age category, A2 — second age category, A3 — third age category. Shape changes (magnified 3 times for the cranium) among categories separated along PC1 axis are visualized by TPS deformation grids 
Table 3 Comparisons of the patterns of covariance for the symmetric (individual variation, Ind) and asymmetric (fluctuating asymmetry, FA) components of shape variation for the mandible and cranium

\begin{tabular}{|c|c|c|c|c|c|c|}
\hline & Shape component & $\mathbf{R}$ & $P$ & Shape component & $\mathbf{R}$ & $P$ \\
\hline \multicolumn{7}{|l|}{ Mandible } \\
\hline$A 1$ versus $A 2$ & Symmetric & 0.923 & $<0.0001$ & Asymmetric & 0.896 & $<0.0001$ \\
\hline$A 1$ versus $A 3$ & Symmetric & 0.925 & $<0.0001$ & Asymmetric & 0.821 & $<0.0001$ \\
\hline$A 2$ versus $A 3$ & Symmetric & 0.921 & $<0.0001$ & Asymmetric & 0.910 & $<0.0001$ \\
\hline \multicolumn{7}{|l|}{ Cranium } \\
\hline$A 1$ versus $A 2$ & Symmetric & 0.855 & $<0.0001$ & Asymmetric & 0.876 & $<0.0001$ \\
\hline$A 1$ versus $A 3$ & Symmetric & 0.829 & $<0.0001$ & Asymmetric & 0.879 & $<0.0001$ \\
\hline$A 2$ versus $A 3$ & Symmetric & 0.855 & $<0.0001$ & Asymmetric & 0.852 & $<0.0001$ \\
\hline
\end{tabular}

Age categories: A1 - first age category, A2 — second age category, A3-third age category. R-matrix correlation. $P$ values are from matrix permutation tests against the null hypothesis of complete dissimilarity between the respective covariance matrices

Table 4 Levels of canalization and developmental stability (DS) for the mandible and cranium

\begin{tabular}{lcllll}
\hline & Var $_{\text {Symmcs }}$ & Var $_{\text {Cs }}$ & Var $_{\text {shape }}$ & SizeFA10a & ShapeFA10a \\
\hline Mandible & & & & & \\
P0 & 6963.96 & - & 0.00098 & 10.78 & 0.00412 \\
P1 & 9780.19 & - & 0.00114 & 13.04 & 0.00377 \\
P2 & 7605.12 & - & 0.00109 & 6.38 & 0.00347 \\
P3 & 3961.81 & - & 0.00125 & 15.48 & 0.00373 \\
Cranium & & $*$ & & & $*$ \\
P0 & - & $19,286.69$ & 0.00038 & - & 0.00132 \\
P1 & - & $22,648.45$ & 0.00040 & - & 0.00136 \\
P2 & - & $22,449.80$ & 0.00041 & - & 0.00131 \\
P3 & - & $10,525.37$ & 0.00040 & - & 0.00134 \\
\hline
\end{tabular}

\footnotetext{
* Significance level at $P<0.01$ after Levene's test
}

Categories regarding parasitism: $\mathrm{P} 0$-non-parasitized animals, $\mathrm{P} 1$-animals parasitized by one nematode species, $\mathrm{P} 2$-animals parasitized by two nematode species, P3 - animals parasitized by three to five nematode species. Var $_{\text {Symmcs }}$ mandibular among-individual size variance; $\operatorname{Var}_{\mathrm{CS}}$ - cranial among-individual size variance; Var $_{\text {shape }}$ - variance in mandibular/cranial shape; SizeFA10a-level of fluctuating asymmetry (FA) for mandibular size; ShapeFA10a-level of fluctuating asymmetry (FA) for mandibular/cranial shape. FA10a $=0.798 \mathrm{VMS}_{\mathrm{sj}}$ $\mathrm{MS}_{\mathrm{m}}$ calculated from the values given in Additional files 4 and 5: Tables $\mathrm{S} 4$ and S5

that CS asymmetry is normally distributed, indicating the absence of antisymmetry in mandibular size within each category regarding parasitism.

Both variance of symmetric CS ( $\operatorname{Var}_{\text {SymmCS }}$ ) for mandibular size and variance of CS $\left(\operatorname{Var}_{\mathrm{CS}}\right)$ for cranial size are the highest in P1 category, followed by P2 and P0 categories, whereas the lowest values are observed in P3 category (Table 4). While these differences among categories regarding parasitism in mandibular size variance are not statistically significant $\left(\mathrm{F}_{3,271}=2.05, P=0.1075\right)$, Levene's test performed on absolute size differences reveals statistically significant differences in cranial size variance $\left(F_{3}\right.$, $316=5.05, P=0.0020)$. Besides, regressions of absolute size differences on dry eye lens mass show the absence of age-related changes in mandibular and cranial size variance in each category regarding parasitism, except in P0 category (mandible: $\mathrm{r}=0.3225, P=0.0288$; cranium: $\mathrm{r}=0.3992, P=0.0023)$ where both mandibular and cranial size variance increased with age (Fig. 4).

For mandibular size the level of FA (SizeFA10a index) is the highest in P3 category, followed by P1 and P0 categories, while the lowest value of SizeFA10a index is observed in P2 category (Table 4). Levene's test performed on asymmetric CS discloses no statistically significant differences in the level of mandibular size FA among categories regarding parasitism $\left(\mathrm{F}_{3,271}=1.36\right.$, $P=0.2540)$. Likewise, regressions of asymmetric CS versus age indicate the absence of the association of individual measures of size FA with age within each category regarding parasitism (P0 category: $r=0.0834$, $P=0.5816$; P1 category: $\mathrm{r}=-0.0854, P=0.4082$; $\mathrm{P} 2$ category: $\mathrm{r}=-0.0942, P=0.3881$; P3 category: $\mathrm{r}=0.0209$, $P=0.8889$ ).

\section{Categories regarding parasitism-Shape}

As presented by parametric F-tests in Procrustes ANOVAs of shape (Additional file 5: Table S5), mandibular and cranial shape variation among individuals, as well as directional asymmetry (DA) and fluctuating asymmetry (FA), are all highly significant in all categories regarding parasitism. Although additional effect of sex is significant in P2 and P3 categories for the mandible and in P2 category for the cranium, it accounts for smaller percentage of the total shape variation than individual variation and FA (mandible-P2 category: Sex $=1.72 \%$; Individual $=81.04 \%$; Ind $\times$ Side $=10.66 \%$; mandibleP3 category: Sex $=3.15 \%$ Individual $=80.34 \%$; Ind $\times$ Side $=10.36 \%$; cranium-P2 category: Sex $=1.31 \%$; Individual $=81.90 \%$; Ind $\times$ Side $=10.48 \%$ ). Additional effect of presence of $\mathrm{B}$ chromosomes (Bs) is significant only 

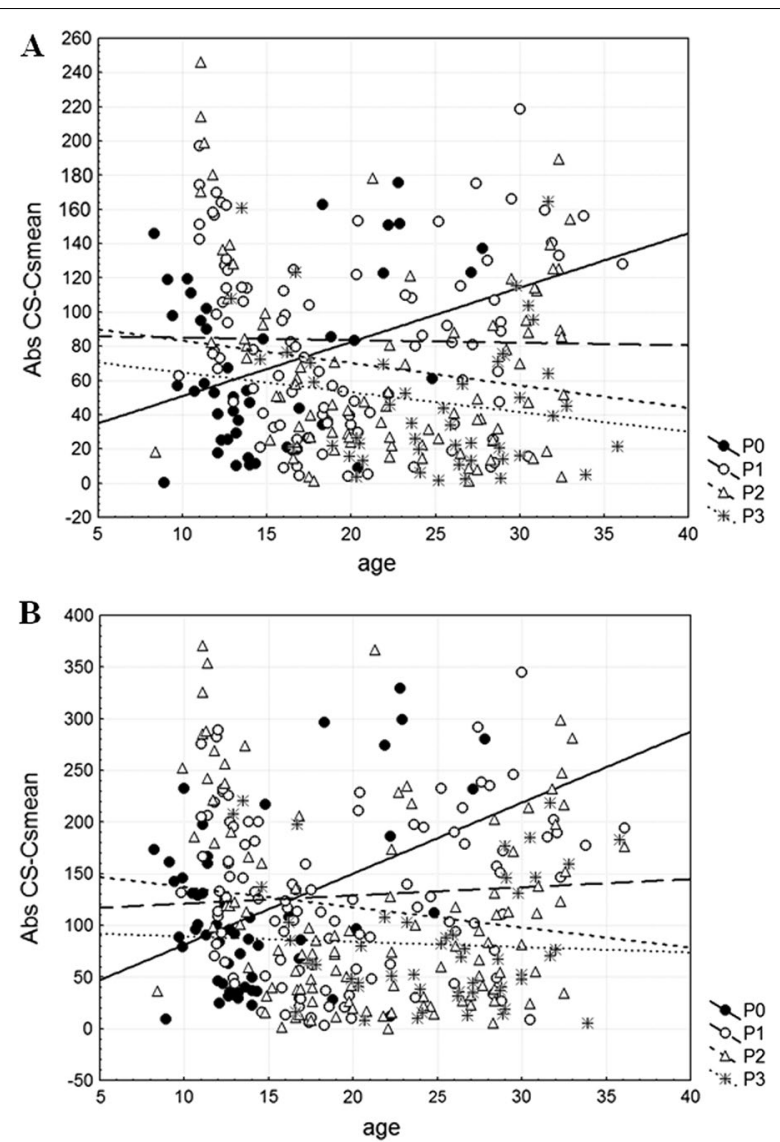

Fig. 4 Regressions of individual measures of size variance (absolute size differences) onto dry eye lens mass (age) within each category regarding parasitism ( $\mathrm{PO}$ —non-parasitized animals, $\mathrm{P} 1$ —animals parasitized by one nematode species, $\mathrm{P} 2$ - animals parasitized by two nematode species, P3 — animals parasitized by three to five nematode species) for the mandible (a) and cranium (b) for the mandible in P1 category where it accounts for smaller percentage of the total shape variation than individual variation and FA $(\mathrm{Bs}=1.94 \%$; Individual $=80.43 \%$; Ind $\times$ Side $=11.59 \%$ ). Although significant, DA accounts for a fairly small percentage of the total mandibular and cranial shape variation (mandible: 1.97\%, 1.14\%, 1.27\%, and $1.06 \%$ in P0, P1, P2, and P3 category, respectively; cranium: $2.18 \%, 1.43 \%, 1.76 \%$, and $2.24 \%$ in $\mathrm{P} 0, \mathrm{P} 1, \mathrm{P} 2$, and P3 category, respectively). In all categories regarding parasitism the visual examinations of the scatter plots for the first five PCs of the vectors of individual signed asymmetries reveal no evidence for clustering of the data points. Additionally, Kolmogorov-Smirnov tests indicate that distributions of each of the five PCs scores don't show a significant departure from normality. Thus, these asymmetries can be assigned to FAs.

For the mandible, among-individual shape variance $\left(\operatorname{Var}_{\text {shape }}\right)$ is the highest in P3 category, followed by P1
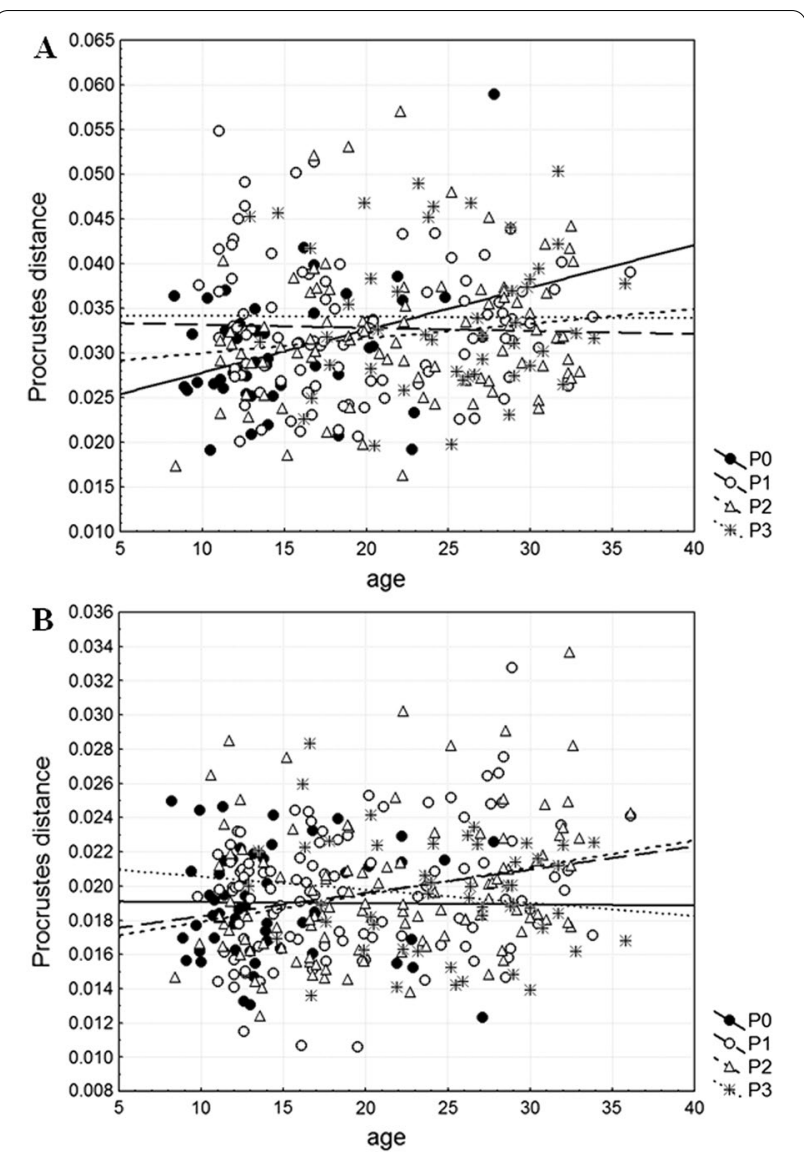

Fig. 5 Regressions of individual measures of shape variance (Procrustes distances, Pds) onto dry eye lens mass (age) within each category regarding parasitism ( $\mathrm{PO}$-non-parasitized animals, P1 — animals parasitized by one nematode species, P2 — animals parasitized by two nematode species, P3 - animals parasitized by three to five nematode species) for the mandible (a) and cranium (b)

and P2 categories, whereas the lowest value is observed in P0 category (Table 4). Levene's test performed on Procrustes distances (Pds) reveal no significant differences in mandibular shape variance among categories regarding parasitism $\left(\mathrm{F}_{3,271}=0.89, P=0.4481\right)$. Regressions of Pds on dry eye lens mass show the absence of age-related changes in mandibular shape variance in each category regarding parasitism, except in P0 category $(r=0.3372$, $P=0.0219)$ where mandibular shape variance increased with age (Fig. 5a). For the cranium, among-individual shape variance ( $\mathrm{Var}_{\text {shape }}$ ) is the highest in P2 category, followed by the same values observed in P1 and P3 categories, whereas the lowest value is observed in $\mathrm{P} 0$ category (Table 4). Levene's test performed on Pds reveal no significant differences in cranial shape variance among categories regarding parasitism $\left(\mathrm{F}_{3,316}=0.82, P=0.4862\right)$. Regressions of Pds on dry eye lens mass show the absence of age-related changes in cranial shape variance in P0 
and P3 categories, but its presence in P1 $(\mathrm{r}=0.2449$, $P=0.0114)$ and $\mathrm{P} 2(\mathrm{r}=0.2856, P=0.0027)$ categories where cranial shape variance increased with age (Fig. 5b).

For mandibular shape the level of FA (ShapeFA10a index) is the highest in P0 category, followed by P1 and P3 categories, whereas the lowest value is observed in P2 category (Table 4). Levene's test performed on shape FA scores discloses no significant differences in the level of mandibular shape FA among categories regarding parasitism $\left(\mathrm{F}_{3,271}=1.89, P=0.1316\right)$. Regressions of mandibular Procrustes FA scores versus age are statistically insignificant within each category regarding parasitism, except in P1 category $(\mathrm{r}=-0.2317, P=0.0231)$ where shape FA scores decreased with age (Fig. 6a). For cranial shape the level of FA (ShapeFA10a index) is the highest in P1 category, followed by P3 and P0 categories, whereas the lowest value is in P2 category (Table 4). Levene's test performed on shape FA scores reveals statistically significant differences in the level of cranial shape FA among categories regarding parasitism $\left(\mathrm{F}_{3,316}=4.26, P=0.0057\right)$. Regressions of cranial Procrustes FA scores versus age are statistically insignificant within each category regarding parasitism, except in P3 category $(r=0.3608, P=0.0101)$ where shape FA scores increased with age (Fig. 6b).

All pairwise comparisons of the analyzed categories regarding parasitism, except $\mathrm{P} 1$ vs. $\mathrm{P} 2(\mathrm{Pd}=0.0076$, $P=0.0123$; non-significant after Bonferroni correction) and $\mathrm{P} 2$ vs. $\mathrm{P} 3(\mathrm{Pd}=0.0069, P=0.2240)$ for the mandible and $\mathrm{P} 1$ vs. $\mathrm{P} 2$ for the cranium $(\mathrm{Pd}=0.0032, P=0.1627)$, show statistically significant mean shape differences in symmetric component of shape variation (mandible: $\mathrm{Pd}$ (P0 vs. $\mathrm{P} 1)=0.0131, P<0.0001 ; \mathrm{Pd}(\mathrm{P} 0$ vs. $\mathrm{P} 2)=0.0175$, $P<0.0001 ; \quad P d \quad(P 0$ vs. $P 3)=0.0221, \quad P<0.0001 ; \quad P d$ (P1 vs. $\mathrm{P} 3)=0.0122, \quad P=0.0001$; cranium: $\mathrm{Pd}$ (P0 vs. $\mathrm{P} 1)=0.0119, P<0.0001 ; \mathrm{Pd}(\mathrm{P} 0$ vs. $\mathrm{P} 2)=0.0136$, $P<0.0001$; Pd (P0 vs. P3) $=0.0199, P<0.0001$; Pd (P1 vs. $\mathrm{P} 3)=0.0086 P<0.0001 ; \mathrm{Pd}(\mathrm{P} 2$ vs. $\mathrm{P} 3)=0.0069$, $P<0.0001)$. Scatterplots of the first two principal components (PC1 and $\mathrm{PC} 2$ ) for symmetric shape variation, demonstrate that for the mandible there is a complete overlap of specimens belonging to four categories regarding parasitism (Fig. 7a), while for the cranium PC1 axis tends to separate non-parasitized ( $\mathrm{P} 0$ category) from the animals parasitized by three to five nematode species (P3 category) (Fig. 7b). However, discriminant function analysis (DFA) between P0 and P3 categories and multivariate regression of their cranial shape variables onto dry eye lens mass reveal similar shape changes (Fig. 7c, d), indicating that variation in the symmetric component of cranial shape variation detected along $\mathrm{P} 1$ axis between $\mathrm{P} 0$ and P3 categories (Fig. 7b) is age-related.

For both mandible and cranium the patterns of symmetric (Ind) and asymmetric (FA) shape variation is
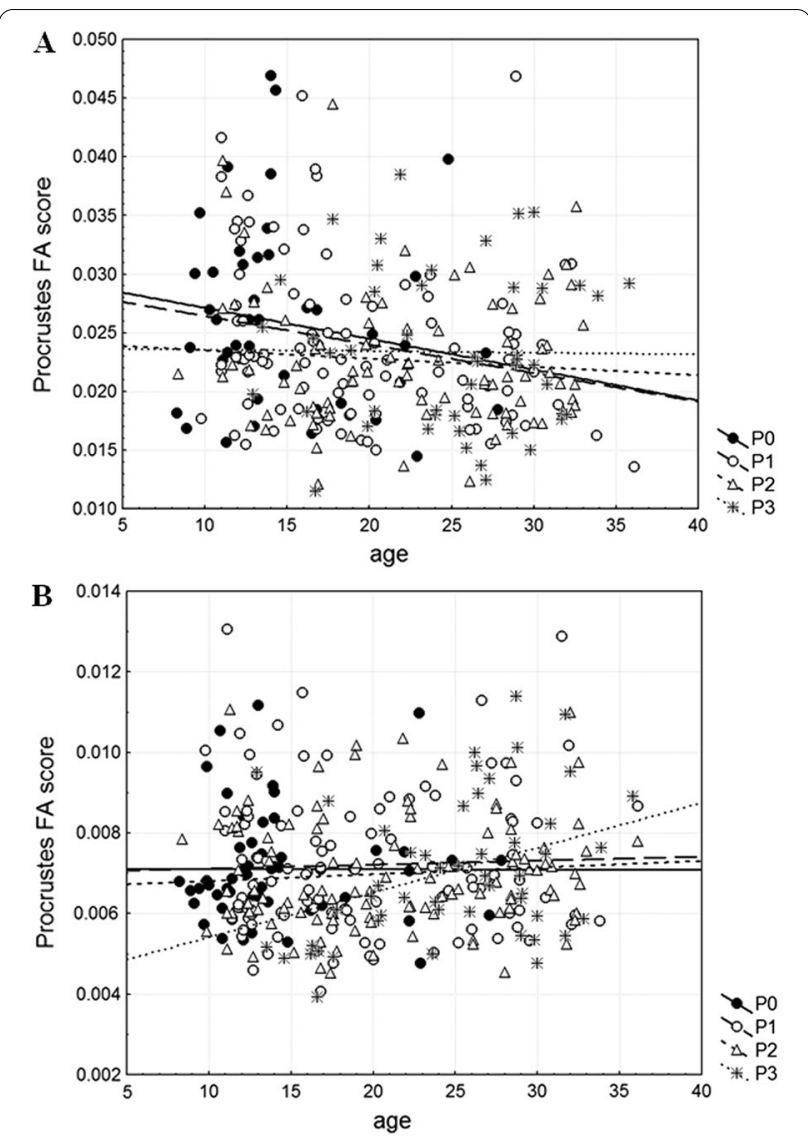

Fig. 6 Regressions of individual measures of shape fluctuating asymmetry (Procrustes FA scores) onto dry eye lens mass (age) within each category regarding parasitism (PO_non-parasitized animals, P1 — animals parasitized by one nematode species, P2 — animals parasitized by two nematode species, $\mathrm{P} 3$ - animals parasitized by three to five nematode species) for the mandible (a) and cranium (b)

similar between all categories regarding parasitism (Table 5).

\section{Discussion}

\section{Age-related canalization and developmental stability}

In contrast to our prediction, mandibular and cranial size variance among Apodemus flavicollis individuals does not decrease with age, indicating the absence of agerelated changes in the level of canalization for mandibular and cranial size. This discrepancy from the previous examinations of laboratory-reared [23, 25, 35], as well as rodents from the wild [49], that documented statistically significant reduction in skull size variance among individuals in older groups of specimens, is probably due to the facts that our study does not include juveniles and that growth is asymptotic in the previous studies.

We detected statistically significant increase of both mandibular and cranial shape variance among A. flavicollis individuals with age, i.e. age-related decline of the level 

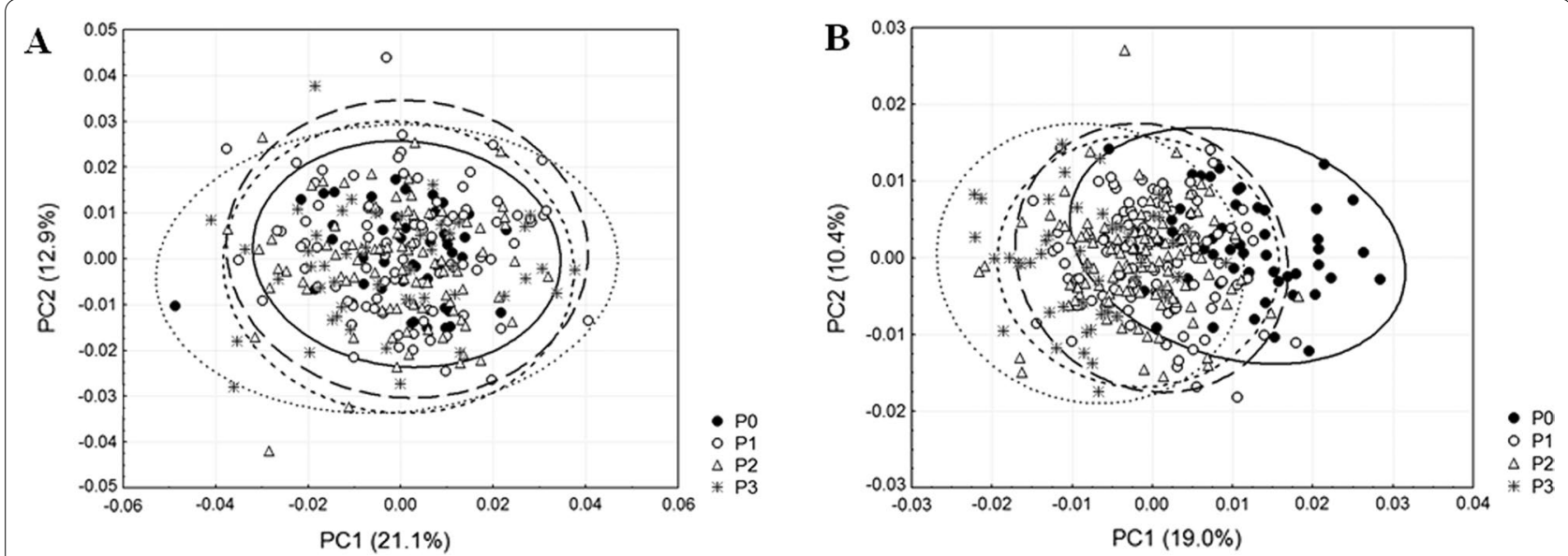

C

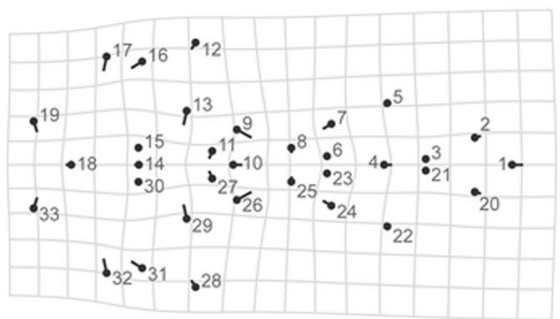

PO
D

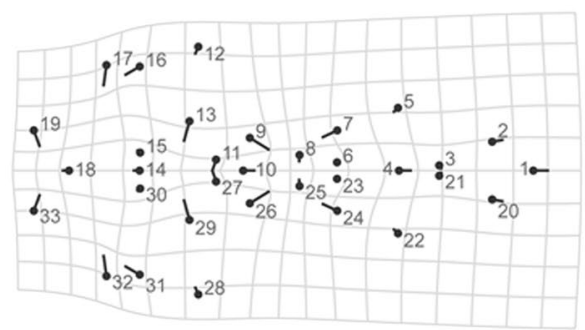

youngest

oldest

Fig. 7 Scatterplots of the first two principal components (PC1 vs. PC2) from the symmetric component of shape variation (individual variation, Ind) for the mandible (a) and cranium (b). Categories regarding parasitism: P0—non-parasitized animals, P1 —animals parasitized by one nematode species, P2 - animals parasitized by two nematode species, P3 - animals parasitized by three to five nematode species. Cranial shape changes (magnified 3 times and visualized by TPS deformation grids) observed from discriminant function analysis (DFA) between P0 and P3 categories (c) and multivariate regression of their shape variables onto dry eye lens mass (d)

Table 5 Comparisons of the patterns of covariance for the symmetric (individual variation, Ind) and asymmetric (fluctuating asymmetry, FA) components of shape variation for the mandible and cranium

\begin{tabular}{|c|c|c|c|c|c|c|}
\hline & Shape component & $\mathbf{R}$ & $P$ & Shape component & $\mathbf{R}$ & $P$ \\
\hline \multicolumn{7}{|l|}{ Mandible } \\
\hline P0 versus P1 & Symmetric & 0.899 & $<0.0001$ & Asymmetric & 0.863 & $<0.0001$ \\
\hline$P 0$ versus $P 2$ & Symmetric & 0.890 & $<0.0001$ & Asymmetric & 0.846 & $<0.0001$ \\
\hline$P 0$ versus $P 3$ & Symmetric & 0.831 & $<0.0001$ & Asymmetric & 0.761 & $<0.0001$ \\
\hline$P 1$ versus $P 2$ & Symmetric & 0.946 & $<0.0001$ & Asymmetric & 0.906 & $<0.0001$ \\
\hline$P 1$ versus $P 3$ & Symmetric & 0.911 & $<0.0001$ & Asymmetric & 0.872 & $<0.0001$ \\
\hline$P 2$ versus $P 3$ & Symmetric & 0.899 & $<0.0001$ & Asymmetric & 0.899 & $<0.0001$ \\
\hline \multicolumn{7}{|l|}{ Cranium } \\
\hline $\mathrm{P} 0$ versus $\mathrm{P} 1$ & Symmetric & 0.819 & $<0.0001$ & Asymmetric & 0.870 & $<0.0001$ \\
\hline$P 0$ versus $P 2$ & Symmetric & 0.841 & $<0.0001$ & Asymmetric & 0.837 & $<0.0001$ \\
\hline$P 0$ versus $P 3$ & Symmetric & 0.804 & $<0.0001$ & Asymmetric & 0.824 & $<0.0001$ \\
\hline$P 1$ versus $P 2$ & Symmetric & 0.890 & $<0.0001$ & Asymmetric & 0.897 & $<0.0001$ \\
\hline$P 1$ versus $P 3$ & Symmetric & 0.836 & $<0.0001$ & Asymmetric & 0.859 & $<0.0001$ \\
\hline$P 2$ versus $P 3$ & Symmetric & 0.844 & $<0.0001$ & Asymmetric & 0.852 & $<0.0001$ \\
\hline
\end{tabular}

Categories regarding parasitism: $\mathrm{P} 0$-non-parasitized animals, $\mathrm{P} 1$-animals parasitized by one nematode species, $\mathrm{P} 2$-animals parasitized by two nematode species, P3 - animals parasitized by three to five nematode species. R - matrix correlation. $P$ values are from matrix permutation tests against the null hypothesis of complete dissimilarity between the respective covariance matrices 
of canalization for mandibular and cranial shape. This result contradicts our prediction, as well as earlier findings of statistically significant reduction in skull shape variance among individuals in older groups of specimens in laboratory-raised rodents $[23,36,37]$. On the other hand, it is in agreement with findings by Willmore et al. [25]. Inspecting the effects of developmental and functional interactions on mouse cranial variability through late ontogeny, Willmore et al. [25] surveyed random-bred mouse skulls aged 35,90 , and 150 days and found that the youngest group ( 35 days old mice) was characterized by the smallest value of among-individual shape variance for mesoderm and basicranial regions, as well as the whole skull. The highest amounts of mandibular and cranial shape variation among $A$. flavicollis individuals observed in the oldest group, i.e. the reduction in the level of canalization for mandibular and cranial shape with age, could be explained by the fact that animals from natural populations, in contrast to those from laboratories, would be exposed to heterogeneous environmental conditions, and their diet would probably differ greatly from that of lab animals, as suggested by Willmore et al. [25]. Accordingly, increased environmental variation would result in increased phenotypic variation which could possibly create changes in variability through late postnatal ontogeny that are not seen in laboratory samples.

Age-related dynamics of the magnitude of A. flavicollis intraindividual mandibular size variation (FA) is not statistically significant. Once again, the absence of differences in the level of DS for mandibular size among age categories may be a consequence of the absence of juveniles in the study sample. However, for mandibular shape, the level of DS increases with age, whereas for cranial shape there are no age-related changes in the level of DS. DS was found to decrease with age postnatally in both macaque and human crania [98]. Nevertheless, Parker and Leamy [99] documented its increase with age in random-bred mouse morphometric characters, while Willmore et al. [25] reported that the degree of FA in random-bred mouse skulls was stable between three age groups (35, 90, and 150 days) for the whole skull, as well as all its regions.

Investigations of laboratory-reared mice and rats [25, $37,100]$, as well as studies that have used specimens from wild rodent populations $[49,101]$, demonstrated that the mean skull shape differed across ontogenetic stages. The values of Procrustes distances for both mandible and cranium of A. flavicollis point to the largest differences in the mean shape between $\mathrm{A} 1$ and A3, followed by $\mathrm{A} 1$ and $\mathrm{A} 2$, and the smallest ones between $\mathrm{A} 2$ and A3 categories. As evident from the PCA scatterplots of the first two principal components ( $\mathrm{PC} 1$ and PC2) for symmetric shape variation, PC1 axis separates age categories. As expected, mandibular and cranial shape changes are most visible between the youngest and the oldest age groups, supporting the earlier findings in rodents $[25,37,49,100,101]$. Concerning shape differences between the successive age categories, there is a similar degree of overlap for the mandible and cranium between $\mathrm{A} 1$ and $\mathrm{A} 2$ categories, whereas between A2 and A3 categories there is a greater degree of overlap for the mandible than for the cranium. Mandibular shape changes between the youngest and two older groups, i.e. the wider posterior mandibular part (in the regions of angular and coronoid processes) and the shorter alveolar region (molar and incisor zones) in older A. flavicollis specimens, are concordant with the ontogenetic mandibular shape variation in eight rodent species observed by Zelditch et al. [102]. These authors noted the general deepening of the horizontal ramus relative to its length (shortening of the mandible anteriorly), the tremendous deepening of the angular process, and a substantial increase in the width of the coronoid process, as well as a reorientation of that process to be more erect, as the most striking mandibular shape similarity between the postnatal ontogenies of the analyzed species, including cotton rat (Sigmodon fulviventer) and house mouse (Mus musculus domesticus). Cranial shape changes between the youngest and the oldest groups, i.e. reduced basicranial region, but longer and narrower facial region in older A. flavicollis specimens, are in agreement with the common postnatal ontogenetic cranial shape changes in tetrapods [103], while contracted regions of the palate and foramen magnum in older $A$. flavicollis are consistent with findings of postnatal ontogenetic cranial shape variation in the yellow-bellied marmot Marmota flaviventris [101] and Martino's vole Dinaromys bogdanovi [49].

Contrary to our prediction, there is no age-related dynamics of covariance structure among A. flavicollis individuals. Likewise, we detected no ontogenetic dynamics of covariance pattern within A. flavicollis individuals. Analyzing covariance structures from age to age in two rodent species, cotton rats (S. fulviventer) and house mice (M. m. domesticus), Zelditch et al. [24] also assessed the overall similarity of covariance matrices by using matrix correlation, but found significant differences in structure of variation, measured by the angles between the subspaces encompassing $80 \%$ of the variation. Moreover, assessing the effect of prenatal nutritional stress on canalization and DS of the laboratory mouse fetal skull, Gonzalez et al. [30] found that the pattern of shape asymmetry was affected by the environmental perturbation, by estimating the angles between the first PCs. Therefore, besides biological, methodological issues cannot be omitted as a possible reason for the failure to detect 
ontogenetic dynamics of covariance structure both among and within A. flavicollis individuals.

\section{Nematode parasitism-related canalization and developmental stability}

Regarding the relationship of nematode parasitism with canalization for mandibular and cranial size and shape in A. flavicollis, we predicted the highest level of canalization in non-parasitized animals (P0 category). Disagreeing with our prediction, the most parasitized category (P3) was characterized by the highest level of canalization observed for mandibular and cranial size. Even though in P0 category the level of canalization for both mandibular and cranial shape is the highest as we expected, we observed no statistically significant differences in mandibular and cranial shape variance among analyzed categories regarding parasitism. In P0 category we detected statistically significant increase of mandibular size and shape variance and cranial size variance with age, indicating age-related decline of the level of canalization in non-parasitized animals. Age-related reduction in the level of canalization for cranial shape is detected in P1 and P2 categories. As concluded previously, age-related reduction in the level of canalization in wild compared to laboratory-reared animals could be explained by differences in environments animals from natural and captive habitats experience. Heterogeneous environmental conditions, particularly diverse diet, would result in increased phenotypic variation through late postnatal ontogeny in wild animals. As infections by parasites may be associated with host diet choice [104], differences in age-related dynamics of the level of canalization between non-parasitized and parasitized animals, as well as between yellow-necked mice parasitized by different number of nematode species, may also be related to potential diet differences between them.

Considering the magnitude of mandibular size and shape variation within A. flavicollis individuals (FA), inconsistent with our prediction, the level of DS for both mandibular size and shape is the highest in P2 category, while the level of DS for mandibular shape is the lowest in P0 category. These differences in the level of mandibular size and shape FA among categories regarding parasitism are not statistically significant. We found statistically significant differences in the level of FA for cranial shape among analyzed categories regarding parasitism. However, contradictory to our prediction, the level of DS for cranial shape is the highest in P2, followed by P0 and P3 category, and the lowest in P1 category. We detected statistically significant association of individual measures of mandibular and cranial shape FA with age. Namely, individual measures of mandibular and cranial shape FA significantly decreased with age for the mandible in the less parasitized category (P1) and increased for the cranium in the most parasitized category (P3). Observed ontogenetic trend in mandibular shape FA in P1 category correspond to that identified within the whole sample for age categories, i.e. the level of DS for mandibular shape increases with age. If parasites directly act on the developmental stability of their hosts by imposing on them a metabolic cost during their ontogeny [52, 56], it is predicted that host developmental instability should be directly related to parasite virulence, parasite load, or both [54,56-58]. Therefore, it seems likely that the detected relationship between cranial shape DS and nematode infections in A. flavicollis is caused by parasitic disruption of host development and their direct effect on host DS, i.e. by the third reason proposed by Møller [52]. It is also possible that yellow-necked mice with higher levels of cranial shape FA will more often be restricted to poor environments with elevated risk of encountering parasites $[14,52,54,55]$ or they may be more susceptible to parasitism [52-54]. Body condition is related to an animal's health, quality or vigour [105] and is indicative of environmental stress [106]. Due to the fact that we found no difference in the body condition indices (BCI) among categories regarding parasitism, we can eliminate second reason proposed by Møller [52]. Since parasites can be a cause of asymmetry, and asymmetry can be an indicator of susceptibility to parasitism [17], it would be unwarranted to single out any of these two reasons suggested by Møller [52].

Discrepancy of the results related to the model systems (mandible/cranium) could be explained by possible trait-specific effects of environmental perturbations and developmental noise acting upon the level of canalization and DS, respectively. Different traits might be affected differently by the same conditions owing to different growth curves or different functions of the traits [107]. Moreover, different morphological traits may vary in their susceptibility to the effects of parasitism [52]. For example, in male reindeer Markusson and Folstad [108] reported that the parasite index was positively correlated to asymmetry in antler length, weight and volume, but not to asymmetry in number of tines or asymmetry in jaw length.

Contradicting our prediction, infections by intestinal nematodes are not associated with mandibular and cranial shape variation among A. flavicollis individuals. Likewise, we reported the absence of statistically significant differences in the pattern of symmetric and asymmetric shape variation between non-parasitized and parasitized A. flavicollis specimens, as well as between yellow-necked mice parasitized by different number of nematode species, for both mandible and cranium. However, as we previously concluded, besides biological, 
methodological issues cannot be omitted as a possible reason for the failure to detect differences in covariance structures.

On a final note, advantages of laboratory-based studies over those that include animals from wild populations are obvious. Studies of experimental developmental biology use animals characterized by low levels of genetic variation, such as inbred mice and rats, and control environmental factors, whereas in natural populations multiple genetic and environmental determinants act on magnitude and pattern of morphological variation. On the other hand, development of a population developmental biology approach based on developmental stability study in natural populations is recognized by Zakharov et al. [4] as particularly promising for solving various problems in a practice of population studies as well as for obtaining information on the state of homeorhesis in nature for developmental biology. Finally, to make reasonable predictions about how a covariance structure among and/ or within individuals, i.e. pattern of canalization and/or DS, might respond to some hypothetical perturbation or change, an alternative approach, as advocated by Hallgrímsson et al. [109], is to combine the analyses of natural populations with model organisms in which the source of covariance is known to some extent or can be controlled.

\section{Conclusions}

Our age-related results partly agree with previous findings in rodents. We observed the absence of age-related changes in the levels of canalization for mandibular and cranial size, but found age-related decline of the level of canalization for mandibular and cranial shape and agerelated increase of the level of DS for mandibular shape. We detected mandibular and cranial shape changes during postnatal ontogeny, but revealed no age-related dynamics of mandibular and cranial covariance structure among individuals. However, no rodent study so far has explored age-related changes in the magnitude of FA for mandibular size or mandibular and cranial FA covariance structure. We found the absence of age-related changes in the level of DS for mandibular size. Likewise, we detected no age-related dynamics of mandibular and cranial FA covariance structure.

This is the first study dealing with the nematode parasitism-related canalization and DS in rodents. We found that categories regarding parasitism differ in the level of canalization for cranial size and the level of DS for cranial shape. We observed differences in age-related dynamics of the level of canalization between non-parasitized and parasitized animals, as well as between yellow-necked mice parasitized by different number of nematode species. As infections by parasites may be associated with host diet choice, these differences between categories regarding parasitism may be related to potential diet differences between them. Individual measures of mandibular and cranial shape FA decreased with age for the mandible in the less parasitized category and increased for the cranium in the most parasitized category. Detected relationship between cranial shape DS and nematode infections in A. flavicollis may be caused by parasitic disruption of host development and their direct effect on host DS or the most parasitized animals may be more susceptible to parasitism. Discrepancy of the results related to the model systems (mandible/cranium) could be explained by trait-specific effects of environmental perturbations and developmental noise acting upon the level of canalization and DS, respectively. Mandibular and cranial shape variation and covariance structure among and within individuals are not affected by the nematode parasitism.

Overall, additional studies concerning both age- and nematode parasitism-related canalization and DS of rodent skulls, particularly those from natural populations, are required before drawing some general conclusions.

\section{Abbreviations}

A1: First age category; A2: Second age category; A3: Third age category; ANOVA: Analysis of Variance; Bs: B chromosomes; CS: Centroid size; DA: Directional asymmetry; DFA: Discriminant Function Analysis; DS: Developmental stability; FA: Fluctuating asymmetry/Within-individual variation/Asymmetric shape variation; GPA: Generalized Procrustes Analysis; Ind: Among-individual variation/Symmetric shape variation; $\mathrm{PO}$ : Non-parasitized animals; P1: Animals parasitized by one nematode species; P2: Animals parasitized by two nematode species; P3: Animals parasitized by three to five nematode species; PCA: Principal Component Analysis; PC1: First principal component; Pd: Procrustes distance.

\section{Supplementary Information}

The online version contains supplementary material available at https://doi. org/10.1186/s12983-021-00439-4.

Additional file 1. Table S1 Anatomical definitions of landmarks recorded on the labial view of the mandible and the ventral surface of the cranium of the yellow-necked field mouse (Apodemus flavicollis)

Additional file 2. Table S2 ANOVAs of centroid size (CS). \% total-percentage of the total size variation. Age categories: A1 - first age category, A2 - second age category, A3 - third age category

Additional file 3. Table S3 Procrustes ANOVAs of shape. \% total-percentage of the total shape variation. Age categories: A1 - first age category, A2 - second age category, A3 - third age category

Additional file 4. Table S4 ANOVAs of centroid size (CS). \% total-percentage of the total size variation. Categories regarding parasitism: P0 - non-parasitized animals, P1 — animals parasitized by one nematode species, P2 - animals parasitized by two nematode species, P3 — animals parasitized by three to five nematode species

Additional file 5. Table S5 Procrustes ANOVAs of shape. \% total-percentage of the total shape variation. Categories regarding parasitism: P0 — non-parasitized animals, P1 — animals parasitized by one nematode species, P2 - animals parasitized by two nematode species, P3-animals parasitized by three to five nematode species 


\section{Acknowledgements}

This work was supported by the Ministry of Education, Science and Technological Development of the Republic of Serbia (Grants No. 173003 and 451-03-9/2021-14/200007). The authors are grateful to Dr. Julien Claude and an anonymous reviewer for their helpful comments on the earlier version of this manuscript.

\section{Authors' contributions}

VJ, MV, and JB designed the study. VJ, VMJ, IB, MV, and JB collected animals. MV collected data regarding the age of animals and cytogenetic data. BČ, OBC, VMJ, and IB collected parasitism-related data. VJ collected 2D geometric morphometric data. Data analysis and interpretation were conducted by $\mathrm{VJ}$ and JB. VJ made the figures and wrote the first draft of the manuscript. All authors edited and approved the final manuscript.

\section{Funding}

This study was founded by the Ministry of Education, Science and Technological Development of the Republic of Serbia (Grants No. 173003 and 451-03-9/2021-14/200007).

\section{Availability of data and materials}

The datasets used and/or analyzed during the current study are available from the corresponding author on reasonable request.

\section{Declarations}

\section{Animal ethics}

The study was conducted under permits issued by the Ministry of Agriculture and Nature Protection, Republic of Serbia (number: 353-03-250/2010-04). The yellow-necked mice were treated according to Directive 2010/63/EU of the European Parliament and the Council of 22 September 2010 on the protection of animals used for scientific purposes. All animal procedures were approved by the Ethical Committee for the Use of Laboratory Animals of the Institute for Biological Research "Siniša Stanković" —National Institute of Republic of Serbia, University of Belgrade.

\section{Consent for publication}

Not applicable.

\section{Competing interests}

The authors have no competing interests to declare on this work.

\section{Author details}

${ }^{1}$ Department of Genetic Research, Institute for Biological Research "Siniša Stanković" - National Institute of Republic of Serbia, University of Belgrade, Belgrade, Serbia. ${ }^{2}$ Department of Biology and Ecology, Faculty of Sciences, University of Novi Sad, Novi Sad, Serbia. ${ }^{3}$ Bioinformatics Solution Center, Freie Universität Berlin, Berlin, Germany. ${ }^{4}$ Human Biology and Primate Evolution, Freie Universität Berlin, Berlin, Germany.

Received: 22 June 2021 Accepted: 7 October 2021 Published online: 24 October 2021

\section{References}

1. Hallgrímsson B, Willmore K, Hall BK. Canalization, developmental stability, and morphological integration in primate limbs. Yearb Phys Anthropol. 2002:45:131-58.

2. Zakharov VM. Future prospects for population phenogenetics. Sov Sci Rev Sect F Physiol Gen Biol Rev. 1989;4:1-80.

3. Zakharov VM. Population phenogenetics: analysis of developmental stability in natural populations. Acta Zool Fenn. 1992;191:7-30.

4. Zakharov VM, Shadrina EG, Trofimov IE. Fluctuating asymmetry, developmental noise and developmental stability: future prospects for the population developmental biology approach. Symmetry. 2020;12:1376.

5. Waddington $\mathrm{CH}$. The canalisation of development and the inheritance of acquired characters. Nature. 1942;150:563.

6. Waddington $\mathrm{CH}$. The strategy of the genes. New York: MacMillan; 1957.
7. Debat V, David P. Mapping phenotypes: canalization, plasticity and developmental stability. Trends Ecol Evol. 2001;16:555-61.

8. Willmore KE, Young NM, Richtsmeier JT. Phenotypic variability: its components, measurement and underlying developmental processes. Evol Biol. 2007;34:99-120.

9. Klingenberg CP. Phenotypic plasticity, developmental instability, and robustness: the concepts and how they are connected. Front Ecol Evol. 2019;7:56.

10. Klingenberg CP, Nijhout HF. Genetics of fluctuating asymmetry: a developmental model of developmental instability. Evolution. 1999;53:358-75.

11. Van Valen LM. A study of fluctuating asymmetry. Evolution. 1962;16:125-42.

12. Palmer AR, Strobeck C. Fluctuating asymmetry: measurement, analysis, patterns. Annu Rev Ecol Syst. 1986;17:391-421.

13. Rutherford SL. From genotype to phenotype: buffering mechanisms and the storage of genetic information. BioEssays. 2000;22:1095-105.

14. Møller AP, Swaddle JP. Asymmetry, developmental stability, and evolution. New York: Oxford University Press, Inc.; 1997.

15. Parsons PA. Fluctuating asymmetry: an epigenetic measure of stress. Biol Rev. 1990;65:131-45.

16. Møller AP, Manning J. Growth and developmental instability. Vet J. 2003;166:19-27.

17. Møller AP. A review of developmental instability, parasitism and disease. Infection, genetics and evolution. Infect Genet Evol. 2006;6:133-40.

18. Willmore KE, Zelditch ML, Young N, Ah-Seng A, Lozanoff S, Hallgrímsson B. Canalization and developmental stability in the Brachyrrhine mouse. J Anat. 2006;208:361-72.

19. Beasley DAE, Bonisoli-Alquati A, Mousseau TA. The use of fluctuating asymmetry as a measure of environmentally induced developmental instability: a meta-analysis. Ecol Indic. 2013;30:218-26.

20. Klingenberg CP. Analyzing fluctuating asymmetry with geometric morphometrics: concepts, methods, and applications. Symmetry. 2015;7:843-934.

21. Debat V, Alibert P, David P, Paradis E, Auffray JC. Independence between developmental stability and canalization in the skull of the house mouse. Proc R Soc Lond B Biol Sci. 2000;267:423-30.

22. Klingenberg CP. Cranial integration and modularity: insights into evolution and development from morphometric data. Hystrix. 2013;24:43-58.

23. Zelditch ML, Lundrigan BL, Garland T. Developmental regulation of skull morphology. I. Ontogenetic dynamics of variance. Evol Dev. 2004;6:194-206.

24. Zelditch ML, Mezey J, Sheets HD, Lundrigan BL, Garland TJ. Developmental regulation of skull morphology II: Ontogenetic dynamics of covariance. Evol Dev. 2006;8:46-60.

25. Willmore KE, Leamy L, Hallgrímsson B. Effects of developmental and functional interactions on mouse cranial variability through late ontogeny. Evol Dev. 2006;8:550-67.

26. Young NM. Function, ontogeny and canalization of shape variance in the primate scapula. J Anat. 2006;209:623-36.

27. Allen D, Leamy LJ. Effects of 2,3,4,8-tetrachloro-p-dioxin on directional and fluctuating asymmetry of mandible characters in mice. Ecotoxicology. 2001;10:167-76.

28. Gonzalez PN, Oyhenart EE, Hallgrímsson B. Effects of environmental perturbations during postnatal development on the phenotypic integration of the skull. J Exp Zool B Mol Dev Evol. 2011;316:547-61.

29. Gonzalez PN, Hallgrímsson B, Oyhenart EE. Developmental plasticity in covariance structure of the skull: effects of prenatal stress. J Anat. 2011;218:243-57.

30. Gonzalez PN, Lotto FP, Hallgrímsson B. Canalization and developmental instability of the fetal skull in a mouse model of maternal nutritional stress. Am J Phys Anthropol. 2014;154:544-53.

31. Leamy LJ, Meagher S, Taylor S, Carroll L, Potts WK. Size and fluctuating asymmetry of morphometric characters in mice: their associations with inbreeding and t-haplotype. Evolution. 2001;55:2333-41.

32. Hallgrímsson B, Dorval CJ, Zelditch ML, German RZ. Craniofacial variability and morphological integration in mice susceptible to cleft lip and palate. J Anat. 2004;205:501-17. 
33. Hallgrímsson B, Willmore K, Dorval C, Cooper DML. Craniofacial variability and modularity in macaques and mice. J Exp Zool B Mol Dev Evol. 2004;302:207-25.

34. Hallgrímsson B, Brown JJY, Ford-Hutchinson AF, Sheets HD, Zelditch ML, Jirik FR. The brachymorph mouse and the developmental-genetic basis for canalization and morphological integration. Evol Dev. 2006;8:61-73.

35. Nonaka K, Nakata M. Genetic variation and craniofacial growth in inbred rats. J Craniofac Genet Dev Biol. 1984;4:271-302.

36. Zelditch ML, Bookstein FL, Lundrigan BL. The ontogenetic complexity of developmental constraints. J Evol Biol. 1993;6:621-41.

37. Hingst-Zaher E, Marcus LF, Cerqueira R. Application of geometric morphometrics to the study of postnatal size and shape changes in the skull of Calomys expulsus. Hystrix. 2000;11:99-113.

38. Leamy LJ, Klingenberg CP, Sherratt E, Wolf JB, Cheverud JM. The genetic architecture of fluctuating asymmetry of mandible size and shape in a population of mice: another look. Symmetry. 2015;7:146-63.

39. Pankakoski E. Epigenetic asymmetry as an ecological indicator in musk rats. J Mammal. 1985;66:52-7.

40. Blagojević J, Vujošević M. B chromosomes and developmental homeostasis in the yellow-necked mouse, Apodemus flavicollis (Rodentia, Mammalia): Effects on nonmetric traits. Heredity. 2004;93:249-54.

41. OleksykTK, Novak JM, Purdue JR, Gashchak SP, Smith MH. High levels of fluctuating asymmetry in populations of Apodemus flavicollis from the most contaminated areas in Chornobyl. J Environ Radioact. 2004;73:1-20

42. Muñoz-Muñoz F, Sans-Fuentes MA, López-Fuster MJ, Ventura J. Variation in fluctuating asymmetry levels across a Robertsonian polymorphic zone of the house mouse. J Zool Syst Evol Res. 2006;44:236-50.

43. Kshnyasev IA, Gileva EA, Borodin AV, Yalkovskaya LE, Zykov SV. Differences between rodent taxa in fluctuating asymmetry of cranial structures. Dokl Biol Sci. 2007:415:273-6.

44. Mikula O, Macholán M. There is no heterotic effect upon developmental stability in the ventral side of the skull within the house mouse hybrid zone. J Evol Biol. 2008;21:1055-67.

45. Jojić V, Blagojević J, Vujošević M. B chromosomes and cranial variability in yellow-necked field mice (Apodemus flavicollis). J Mammal. 2011;92:396-406

46. Maestri R, Fornel R, Galiano D, de Freitas TRO. Niche suitability affects development: skull asymmetry increases in less suitable areas. PLoS ONE. 2015;10:e0122412.

47. Yalkovskaya LE, Fominykh MA, Mukhacheva SV, Davydova YuA, Borodin AV. Fluctuating asymmetry of rodent cranial structures in an industrial pollution gradient. Russ J Ecol. 2016;47:281-8.

48. Breno M, Leirs H, Van Dongen $\mathrm{S}$. No relationship between canalization and developmental stability of the skull in a natural population of Mastomys natalensis (Rodentia: Muridae). Biol J Linn Soc. 2011;104:207-16.

49. Klenovšek T, Jojić V. Modularity and cranial integration across ontogenetic stages in Martino's vole, Dinaromys bogdanovi. Contrib Zool. 2016:85:275-89.

50. Lalis A, Evin A, Janier M, Koivogui L, Denys C. Host evolution in Mastomys natalensis (Rodentia: Muridae): An integrative approach using geometric morphometrics and genetics. Integr Zool. 2015;10:505-14.

51. Artois J, Blasdell K, Duong V, Buchy P, Hul V, Morand S, Claude J. Effects of mammarenavirus infection (Wēnzhōu virus) on the morphology of Rattus exulans. Infect Genet Evol. 2018;63:404-9.

52. Møller AP. Parasitism and developmental instability of hosts: a review. Oikos. 1996;77:189-96.

53. Møller AP. Elm, Ulmus glabra, leaf asymmetry and dutch elm disease. Oikos. 1999:85:109-16.

54. Alibert P, Bollache L, Corberant D, Guesdon V, Cézilly F. Parasitic infection and developmental stability: fluctuating asymmetry in Gammarus pulex infected with two acanthocephalan species. J Parasitol. 2002;88:47-54.

55. Rantala MJ, Ahtiainen JJ, Suhonen J. Fluctuating asymmetry and immune function in a field cricket. Oikos. 2004;107:479-84.

56. Polak M. Parasites increase fluctuating asymmetry of male Drosophila nigrospiracula: Implication for sexual selection. Genetica. 1993;89:255-65

57. Agnew P, Koella JC. Virulence, parasite mode of transmission, and host fluctuating asymmetry. Proc R Soc Lond B Biol Sci. 1997;264:9-15.

58. Thomas F, Ward DF, Poulin R. Fluctuating asymmetry in an insect host: a big role for big parasites? Ecol Lett. 1998;1:112-7.
59. Mészáros F, Murai E. Contribution to the knowledge of helminths of rodents in Roumania. Parasit Hung. 1979;12:55-70.

60. Genov T. Helminths of Insectivorous Mammals and Rodents in Bulgaria. Sofia: Bulgarian Academy of Sciences; 1984.

61. Grikieniene J. Investigations into endoparasites of small mammals in the environs of lake Drukšiai. Acta Zool Litu. 2005;15:109-14.

62. Ondríková J, Miklisová D, Ribas A, Stanko M. The helminth parasites of two sympatric species of the genus Apodemus (Rodentia, Muridae) from south-eastern Slovakia. Acta Parasitol. 2010;55:369-78.

63. Čabrilo B, Jovanović VM, Bjelić-Čabrilo O, Budinski I, Blagojević J, Vujošević M. Diversity of nematodes in the yellow-necked field mouse Apodemus flavicollis from the Peripannonic region of Serbia. J Helminthol. 2016;90:14-20.

64. Čabrilo B. Diversity and ecology of intestinal nematodes of the yellownecked mouse (Apodemus flavicollis Melchior, 1834) on the territory of Serbia. D. Phil. Thesis. Novi Sad: University of Novi Sad; 2017.

65. Čabrilo B, Jovanović VM, Bjelić-Čabrilo O, Budinski I, Blagojević J, Vujošević $\mathrm{M}$. Is there a host sex bias in intestinal nematode parasitism of the yellow-necked mouse (Apodemus flavicollis) at Obedska bara pond, Serbia? Helminthologia. 2018:55:247-50.

66. Jovanović VM, Čabrilo B, Budinski I, Bjelić-Čabrilo O, Adnađević T, Blagojević J, et al. Host B chromosomes as potential sex ratio distorters of intestinal nematode infrapopulations in the yellow-necked mouse (Apodemus flavicollis). J Helminthol. 2019;93:552-8.

67. Wilson EB. Studies on chromosomes. V. The chromosomes of Metapodius. A contribution to the hypothesis of the genetic continuity of chromosomes. J Exp Zool. 1906;6:147-205.

68. Soldatović B, Savić I, Seth P, Reichstein H, Tolksdorf M. Comparative karyological study of the genus Apodemus. Acta Vet. 1975;25:1-10.

69. Vujošević M, Živković S. Numerical chromosome polymorphism in Apodemus flavicollis and A. sylvaticus (Mammalia: Rodentia) caused by supernumerary chromosomes. Acta Vet. 1987;37:81-92.

70. Vujošević M, Blagojević J. B chromosomes in populations of mammals. Cytogenet Genome Res. 2004;106:247-56.

71. Vujošević M, Rajičić M, Blagojević J. B chromosomes in populations of mammals revisited. Genes. 2018;9:487.

72. Blagojević J, Vujošević M. Do B chromosomes affect morphometric characters in yellow-necked mice Apodemus flavicollis. Acta Theriol. 2000;45:129-35.

73. Vujošević M, Jojić V, Bugarski-Stanojević V, Blagojević J. Habitat quality and $B$ chromosomes in the yellow-necked mouse Apodemus flavicollis. Ital J Zool. 2007;74:313-6.

74. Blagojević J, Stamenković G, Jojić Šipetić V, Bugarski-Stanojević V, Adnađević T, Vujošević M. B chromosomes in populations of yellownecked mice-stowaways or contributing genetic elements? Ital J Zool. 2009:76:250-7.

75. Jojić V, Blagojević J, Ivanović A, Bugarski-Stanojević V, Vujošević M. Morphological integration of the mandible in yellow-necked field mice: the effects of B chromosomes. J Mammal. 2007;88:689-95.

76. Jojić V, Blagojević J, Vujošević M. Two-module oganization of the mandible in the yellow-necked mouse: a comparison between two different morphometric approaches. J Evol Biol. 2012;25:2489-500.

77. AdnađevićT, Jovanović VM, Blagojević J, Budinski I, Čabrilo B, BjelićČabrilo $\mathrm{O}$, et al. Possible influence of $\mathrm{B}$ chromosomes on genes included in immune response and parasite burden in Apodemus flavicollis. PLoS ONE. 2014;9:e112260.

78. Hayward AD. Causes and consequences of intra- and inter-host heterogeneity in defence against nematodes. Parasite Immunol. 2013;35:362-73.

79. Bugarski-Stanojević $\vee$, Blagojević J, Adnađević T, Jovanović V, Vujošević M. Identification of the sibling species Apodemus sylvaticus and A. flavicollis (Rodentia, Muridae) — comparison of molecular methods. Zool Anz. 2013;252:579-87.

80. Hsu TC, Patton JL. Bone marrow preparations for chromosome studies. In: Benirschke K, editor. Comparative Mammalian Cytogenetics. Berlin/ Heidelberg/New York: Springer; 1969. p. 454-60.

81. Malkov S, Vujošević M, Jovanović A. One method for automatic chromosome analysis and comparison. In: Proceedings of 12th Panhelenic Conference in Mathematics Education (Mathematics and Other Sciences). Heraclion, Crete, Greece; 1997. p. 371-378. 
82. Nabagło L, Pachinger K. Eye lens weight as an age indicator in yellownecked mice. Acta Theriol. 1979;24:118-22.

83. Ryzhikov KM, Gvozdev EV, Tokobaev MM, Shaldybin LS, Matsaberidze GV, Merkusheva IV, et al. Key to the helminth parasites of rodents from the fauna of the USSR. Roundworms and acanthocephalans. Moscow: Izdatelstvo „Nauka"; 1979.

84. Rohlf FJ. The tps series of software. Hystrix. 2015;26:9-12.

85. Rohlf FJ. TpsDig. Version 2.30. New York: Department of Ecology and Evolution. State University of New York, Stony Brook NY; 2017. http:// www.sbmorphometrics.org/. Accessed 3 Mar 2017.

86. Klingenberg CP, McIntyre GS. Geometric morphometrics of developmental instability: analyzing patterns of fluctuating asymmetry with Procrustes methods. Evolution. 1998;52:1363-75.

87. Klingenberg CP, Barluenga M, Meyer A. Shape analysis of symmetric structures: quantifying variation among individuals and asymmetry. Evolution. 2002;56:1909-20.

88. Jakob EM, Marshall SD, Uetz GW. Estimating fitness: a comparison of body condition indices. Oikos. 1996;77:61-7.

89. Rohlf FJ, Slice D. Extensions of the Procrustes method for the optimal superimposition of landmarks. Syst Zool. 1990;39:40-59.

90. Dryden IL, Mardia KV. Statistical shape analysis. New York: Wiley; 1998.

91. Rohlf FJ. Shape statistics: Procrustes superimpositions and tangent spaces. J Classif. 1999;16:197-223.

92. Palmer AR, Strobeck C. Fluctuating asymmetry analyses revisited. In: Polak M, editor. Developmental instability: causes and consequences. Oxford: Oxford University Press; 2003. p. 279-319.

93. Zelditch ML, Swiderski DL, Sheets DH, Fink WL. Geometric morphometrics for biologists: a primer. San Diego: Elsevier Academic; 2004.

94. Bookstein FL. Morphometric tools for landmark data: geometry and biology. Cambridge: Cambridge University Press; 1991.

95. Cheverud JM, Wagner GP, Dow MM. Methods for the comparative analysis of variation patterns. Syst Zool. 1989;38:201-13.

96. StatSoft Inc. Statistica for Windows (Computer Program Manual). Tulsa; 1997.

97. Klingenberg CP. MorphoJ: an integrated software package for geometric morphometrics. Mol Ecol Resour. 2011;11:353-7.

98. Hallgrímsson B. Ontogenetic patterning of skeletal fluctuating asymmetry in rhesus macaques and humans: evolutionary and developmental implications. Int J Primatol. 1999;20:121-51.
99. Parker LT, Leamy L. Fluctuating asymmetry of morphometric characters in house mice: the effects of age, sex, and phenotypical extremeness in a random bred population. J Hered. 1991;82:145-50.

100. Zelditch ML, Lundrigan BL, Sheets HD, Garland T Jr. Do precocial mammals develop at a faster rate? A comparison of rates of skull development in Sigmodon fulviventer and Mus musculus domesticus. J Evol Biol. 2003;16:708-20.

101. Cardini A, O'Higgins P. Post-natal ontogeny of the mandible and ventral cranium in Marmota species (Rodentia, Sciuridae): allometry and phylogeny. Zoomorphology. 2005;124:189-203.

102. Zelditch ML, Calamari ZT, Swiderski DL. Disparate postnatal ontogenies do not add to the shape disparity of infants. Evol Biol. 2016;43:188-207.

103. Emerson SB, Bramble DM. Scaling, allometry and skull design. In: Hanken J, Hall BK, editors. The Skull. Functional and Evolutionary Mechanisms, vol. 3. Chicago: The University of Chicago Press; 1993. p. 384-421.

104. Lozano GA. Optimal foraging theory: a possible role for parasites. Oikos. 1991;60:391-5.

105. Peig J, Green AJ. The paradigm of body condition: a critical reappraisal of current methods based on mass and length. Funct Ecol. 2010;24:1323-32

106. Iglesias-Carrasco M, Martín J, Cabido C. Urban habitats can affect body size and body condition but not immune response in amphibians. Urban Ecosyst. 2017;20:1331-8.

107. Knierim U, Van Dongen S, Forkman B, Tuyttens FAM, Špinka M, Campo $J \mathrm{~L}$, et al. Fluctuating asymmetry as an animal welfare indicator-A review of methodology and validity. Physiol Behav. 2007;92:398-421.

108. Markusson E, Folstad I. Reindeer antlers: visual indicators of individual quality? Oecologia. 1997;110:501-7.

109. Hallgrímsson B, Jamniczky H, Young NM, Rolian C, Parsons TE, Boughner JC, et al. Deciphering the palimpsest: studying the relationship between morphological integration and phenotypic covariation. Evol Biol. 2009:36:355-76.

\section{Publisher's Note}

Springer Nature remains neutral with regard to jurisdictional claims in published maps and institutional affiliations.
Ready to submit your research? Choose BMC and benefit from:

- fast, convenient online submission

- thorough peer review by experienced researchers in your field

- rapid publication on acceptance

- support for research data, including large and complex data types

- gold Open Access which fosters wider collaboration and increased citations

- maximum visibility for your research: over $100 \mathrm{M}$ website views per year

At BMC, research is always in progress.

Learn more biomedcentral.com/submissions 